\title{
DATAÇÃO ABSOLUTA POR LUMINESCÊNCIA DO ALOGRUPO \\ ALTO RIO PARANÁ (SP, PR E MS)
}

\author{
Alethea Ernandes Martins SALLUN \\ Kenitiro SUGUIO
}

\begin{abstract}
RESUMO
O Alogrupo Alto Rio Paraná é uma unidade estratigráfica de idade quaternária, que ocorre na Bacia Hidrográfica do Alto Rio Paraná (SP, PR e MS), constituída de depósitos sedimentares de origem coluvial da Aloformação Paranavaí e aluvial da Aloformação Paraná. Esses depósitos foram datados por Termoluminescência (TL) e Luminescência Opticamente Estimulada (LOE), que indicaram idades absolutas deposicionais entre $6.200 \pm 750$ e $980.000 \pm 100.000$ anos A.P. para a Alofomação Paranavaí, e $14.000 \pm 2.000$ e $240.000 \pm 30.000$ anos A.P. para a Aloformação Paraná. As idades obtidas mostram que o Alto Rio Paraná está ativo, no mínimo, desde cerca de 1 $\mathrm{Ma}$ até os dias atuais, atuando no afeiçoamento do relevo por processos construtivos (terraços) e destrutivos (dissecação). Os eventos que propiciaram essa sedimentação possivelmente testemunharam mudanças paleoclimáticas e/ou atividades neotectônicas, que causaram flutuações nos níveis de base com conseqüentes transformações do relevo.
\end{abstract}

Palavras-chave: datação absoluta, luminescência, Quaternário, Alogrupo Alto Rio Paraná

\section{ABSTRACT}

The Alto Rio ParanáAllogroup is a Quaternary stratigraphic unit of the Upper Paraná River Hydrographic Basin (São Paulo, Paraná and Mato Grosso do Sul), constituted by the Paranavaí Alloformation (colluvial deposits) and the Paraná Alloformation (alluvial deposits). These deposits have been dated by Thermoluminescence (TL) and Optically Stimulated Luminescence (OSL) methods, which indicated absolute depositional ages

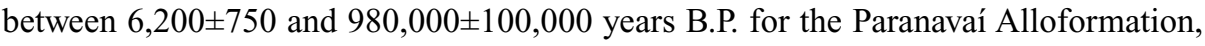

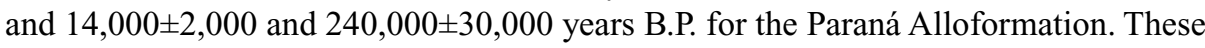
ages show that the Upper Paraná River was active during the last million years in modeling relief by both constructive (terraces) and destructive (dissection) processes. These events are probably related to palaeoclimatic changes and/or neotectonic activities, which gave rise to base level fluctuations and, consequently, transformations of topographic relief.

Keywords: absolute dating, luminescence, Quaternary, Upper Paraná River Allogroup

\section{INTRODUÇÃO}

Datações absolutas por Termoluminescência (TL) e Luminescência Opticamente Estimulada (LOE) foram empregadas para determinar as idades dos extensos depósitos quaternários da Bacia Hidrográfica do Alto Rio Paraná, em partes das regiões centro-oeste, sudeste e sul do Brasil, que foram reunidos no Alogrupo Alto Rio Paraná (SALLUN et al. 2007a). Esses depósitos testemunham importantes eventos geológicos regionais do Cenozóico, mas para melhor elucidar a sua história geológica foram obtidas idades absolutas destes depósitos.

A datação absoluta por luminescência é o único método geocronológico que permite obter, com grande potencialidade, a idade deposicional (DULLER 2004) de depósitos siliciclásticos quaternários, sem restos orgânicos. Ela alcança idades de até 1,5 Ma e, portanto, abrange parte importante do Pleistoceno. 
Os depósitos quaternários da área de estudo (Figura 1) exibem composição essencialmente siliciclástica (areia quartzosa), indicando a possibilidade do uso do método da luminescência para datação absoluta. Na região entre Marília e Presidente Prudente (SP), SALLUN \& SUGUIO (2006) e TATUMI et al. (2006) realizaram datações por luminescência em depósitos sedimentares da Aloformação Paranavaí, que forneceram idades de até $1 \mathrm{Ma}$, indicando que esse método poderia ser empregado em outras áreas de ocorrência desta unidade geológica.

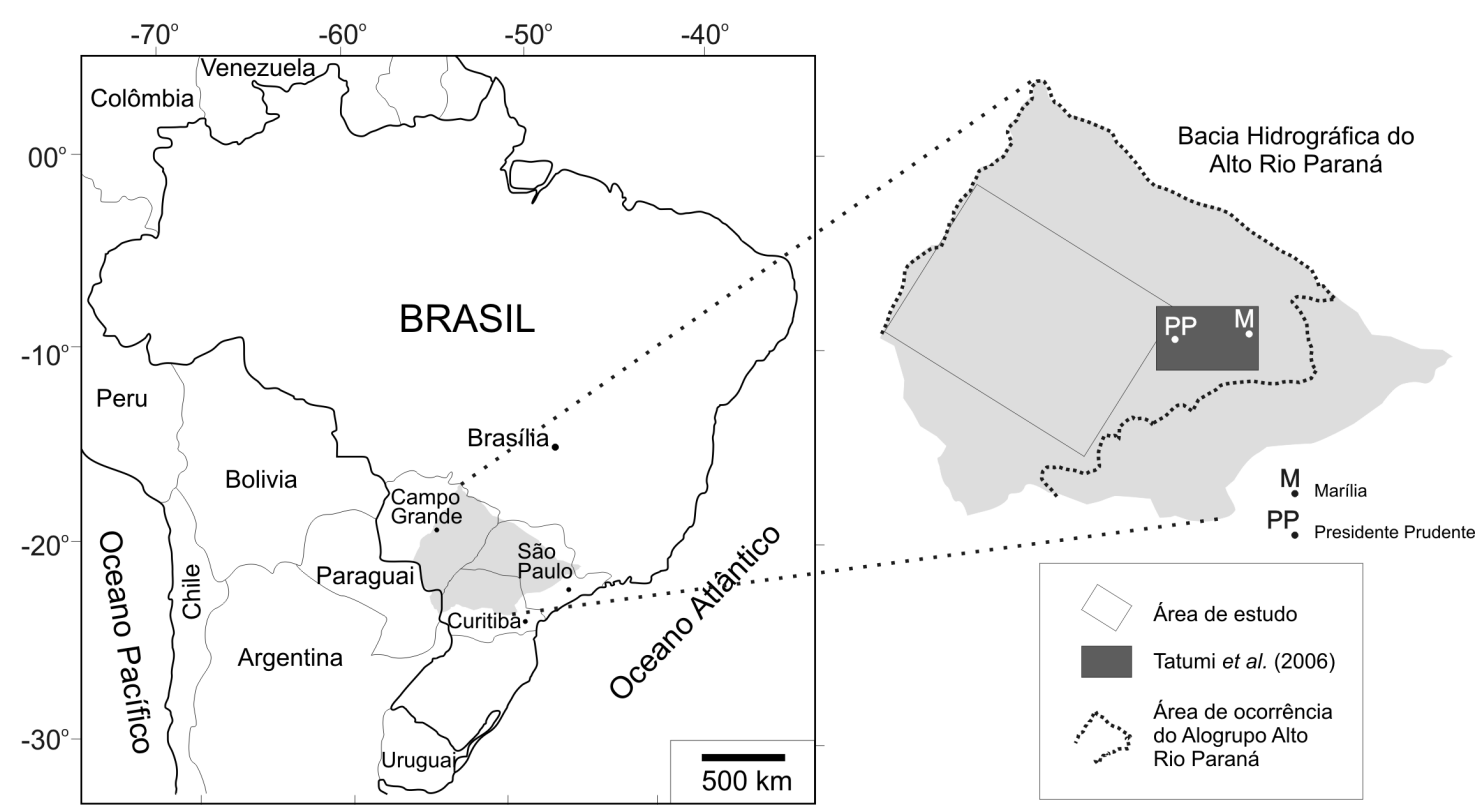

FIGURA 1 - Situação geográfica da área de estudo na Bacia Hidrográfica do Alto Rio Paraná e localização da área onde foram realizadas datações por luminescência por TATUMI et al. (2006).

\section{CONTEXTO GEOLÓGICO}

Depósitos cenozóicos arenosos de origem coluvial podem ser encontrados em diversas localidades das regiões sul, sudeste e centro-oeste do Brasil. Esses depósitos já receberam diferentes denominações, como Formação Paranavaí (SP, PR e MS), Formação Piquerobi (SP) e Formação Cachoeirinha (MS e MT), e recentemente SALLUN et al. (2007a) propuseram formalmente a Aloformação Paranavaí.

POPP e BIGARELLA (1975) denominaram de Formação Paranavaí, em forma preliminar e não formal, a cobertura quaternária arenosa de origem colúvio-aluvial, que se estende pelo noroeste paranaense, oeste paulista e sudoeste do Mato Grosso do Sul. Esta "formação", mencionada anteriormente por KAVALERIDZE (1963), encontra-se superposta a arenitos da Formação Caiuá e basaltos da Formação Serra Geral, exibindo em algumas localidades do Mato Grosso do Sul depósitos rudáceos (seixos de quartzo e basalto) de $60 \mathrm{~cm}$ de espessura.
SANTOS (1997) descreve esses depósitos como uma unidade pedoestratigráfica, devido à origem eluvionar em algumas porções. No vale do Rio Ivaí, DEHIRA et al. (1981) descreveram depósitos coluviais arenosos correlacionáveis à Formação Paranavaí. JUSTUS (1985) incluiu na Formação Paranavaí as carapaças e couraças ferruginosas pedogenéticas encontradas principalmente no divisor das bacias dos rios Ivaí e Piquiri (PR). GASPARETTO (1999) descreveu informalmente como "formações superficiais" depósitos de textura arenosa encontrados na região noroeste do Paraná, que seriam originados dos arenitos da Formação Caiuá por alteração in situ. Estas formações estariam, segundo este autor, relacionadas a superfície $\mathrm{Pd}_{1}$ de erosão definida por BIGARELLA \& ANDRADE (1965), a qual, desde o final do período Terciário, vem sendo remodelada sob condições climáticas que, durante o Quaternário, se alternaram entre períodos mais secos e mais úmidos que o clima atual. 
CORRÊA et al. (1976) descrevem no Planalto de Maracaju (MS) sedimentos arenosos com corpos nodulares ou concrecionários e irregulares de canga e localmente cascalhos, que ocorreriam sobre diversas unidades litoestratigráficas da Bacia do Paraná, correlacionando-os à "Formação Cachoeirinha" de idade supostamente terciária. A designação "Formação Cachoeirinha" teria sido atribuída por GONÇALVES \& SCHNEIDER (1970) na Chapada dos Guimarães (MT) para os depósitos anteriormente denominados como "Formação Superior" (OLIVEIRA 1964) e Unidade C (OLIVEIRA \& MÜHLMANN 1967), em levantamentos realizados pela PETROBRÁS. OLIVA et al. (1979) e SCHOBBENHAUS FILHO \& OLIVA (1979) mapearam sedimentos arenosos e lateritos encontrados nos topos dos planaltos da borda noroeste da Bacia Sedimentar do Paraná como "Cobertura Detrítico-Laterítica e/ou Arenosa". Esses sedimentos inconsolidados, castanho-avermelhados, com leitos de seixos basais, parcialmente laterizados e preservados em superfície de aplainamento sobre o planalto, estariam ligados à "Formação Cachoeirinha". DEL'ARCO et al. (1982) constataram, que nos depósitos de cobertura dos planaltos das chapadas dos Guimarães (MT) e Maracaju (MS) ocorrem elúvios e colúvios sustentados por níveis lateríticos, que poderiam ou não estar relacionados com a "Formação Cachoerinha". Essa unidade, segundo os autores, é pedoestratigráfica, apresenta distribuição descontínua, devido à atuação de processos erosivos, com concreções limoníticas formando pequenos blocos.

No extremo oeste de São Paulo, SUAREZ (1976, 1991) descreveu informalmente como "Formação Piquerobi" os depósitos cenozóicos areno-argilosos e avermelhados, levemente compactados, com freqüentes linhas-de-pedra (stone-lines) interpretadas como de provável origem fluvial e concreções ferruginosas de natureza limonítica na base. Segundo o autor estes depósitos ocorreriam superpostos em discordância erosiva sobre a Superseqüência Bauru, associados a restos da Superfície Neogênica (Terciário Superior), definida por AB'SABER (1969).

SALLUN (2003) descreveu depósitos cenozóicos que ocorrem extensivamente entre Marília e Presidente Prudente, superpostos em discordância (com concentrações basais de ferricretes e/ou linhas-de-pedra) sobre rochas cretácicas da Superseqüência Bauru. Os depósitos foram agrupados em depósitos colúvio-eluviais e aluviais segundo critérios sedimentológicos, morfológicos e genéticos.

SALLUN et al. (2007a) definiram formalmente como Alogrupo Alto Rio Paraná as unidades estratigráficas quaternárias que ocorrem sobre rochas cretáceas da Bacia do Paraná na Bacia Hidrográfica do Alto Rio Paraná. O Alogrupo Alto Rio Paraná é constituído da Aloformação Paranavaí (depósitos coluviais) e Aloformação Paraná (depósitos aluviais) (Figura 2).

A Aloformação Paranavaí é constituída por depósitos arenáceos e rudáceos homogêneos, maciços, com espessura exposta de até $17 \mathrm{~m}$. É composta por areia muito fina a grossa, inconsolidada, com coloração avermelhada. O limite superior corresponde ao horizonte formado por pedogênese atual e o inferior é representado pelo contato com as rochas cretáceas da Bacia do Paraná (Superseqüências Bauru e Goundwana III), onde podem ocorrer camadas centimétricas de nódulos e fragmentos de ferricretes e de linhasde-pedra. Texturalmente os depósitos coluviais da Aloformação Paranavaí mostram distribuição granulométrica homogênea com freqüência muito maior de sedimentos com distribuições areia e areia argilosa (SALLUN et al. 2007a). Sobre a Formação Marília ocorrem depósitos coluviais rudáceos, representativos de intenso intemperismo, provavelmente formados in situ à partir de curto transporte por rastejo. São ortoconglomerados, em geral oligomíticos e sem arranjo interno, que contêm desde grânulos a matacões subarredondados a arredondados, características provavelmente herdadas da rocha matriz. Os fragmentos exibem contatos pontuais e localmente côncavoconvexos, cujos diâmetros maiores podem chegar a $15 \mathrm{~cm}$. Os seixos predominantes são de quartzo e quartzito, além de raros seixos de sílex e basalto. A matriz argilosa não ultrapassa $15 \% \mathrm{e}$, além disso, ocorrem intercalações de camadas arenosas com até $15 \mathrm{~cm}$ de espessura.

SALLUN et al. (2007a) optaram por adotar o nome "Paranavaí" para designar os sedimentos arenosos avermelhados suscetíveis à erosão, que ocorrem na Bacia Hidrográfica do Alto Rio Paraná, por ser um nome já utilizado no meio geológico, sugerido informalmente para uma unidade litoestratigráfica por POPP \& BIGARELLA (1975).

A Aloformação Paraná é composta de depósitos aluviais associados à paleodrenagem do Alto Rio Paraná, bem como do seu curso atual e afluentes, embutidos na Aloformação Paranavaí, 


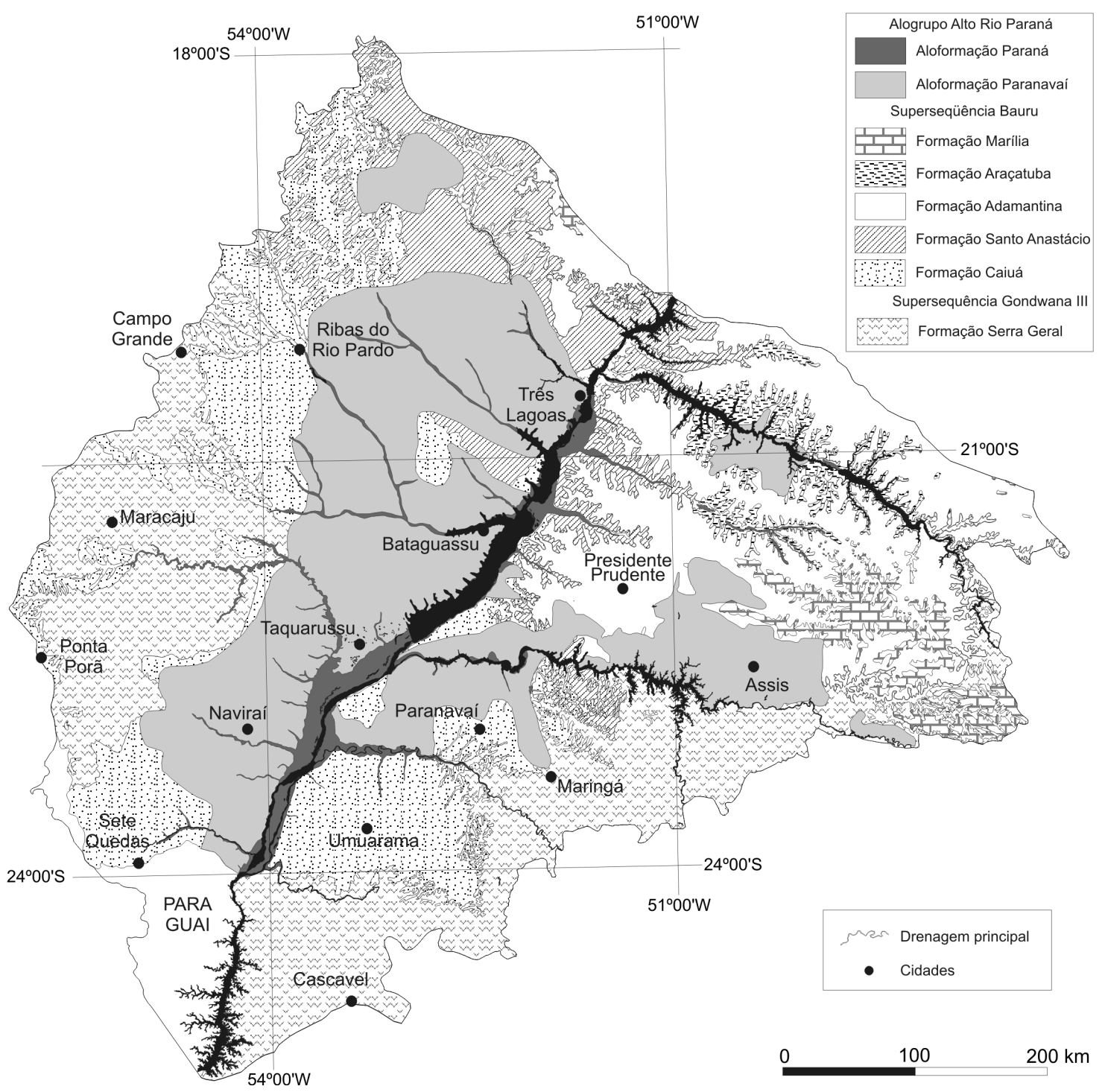

FIGURA 2 - Mapa geológico da área de ocorrência do Alogrupo Alto Rio Paraná (Modificado de BATEZELLI 1998, FERNANDES 1998, FERNANDES \& COIMBRA 1996, BIZZI et al. 2001, MINEROPAR 2001, DEL'ARCO et al. 1982, SALLUN et al. 2007c).

sendo reconhecidos os alomembros Fazenda Boa Vista, Alto Paraná, Paranapanema e Rio do Peixe (SALLUN et al. 2007a). Os terraços aluviais situam-se em diversos níveis topográficos (altos, médios e baixos) em ambas as margens do Alto Rio Paraná. Os terraços são compostos de depósitos maciços arenáceos e rudáceos (areia com níveis de cascalhos e conglomerado limonitizado), de coloração esbranquiçada a cinza escuro, com diversas fácies sedimentares, que indicam a presença de depósitos de canal, lençol arenoso, planície de inundação, dique marginal, bacia de inundação, rompimento de dique marginal, lagoas e barras arenosas de meandros (STEVAUX 1993). Os depósitos lacustres, de lagoas alojadas sobre os sedimentos da Aloformação Paranavaí, também estão relacionados à Aloformação Paraná.

Datações realizadas por TL e LOE forneceram idade pleistocênica para os depósitos da Aloformação Paranavaí $(9.000 \pm 1.000$ a $980.000 \pm 100.000$ anos A.P.) e da Aloformação Paraná (14.000 \pm 2.000 a 240.000 \pm 30.000 anos A.P), que ocorrem entre Marília e Presidente Prudente (SALLUN \& SUGUIO 2006, TATUMI et al. 2006). 


\section{MATERIAIS E MÉTODOS}

As idades dos materiais podem ser calculadas pelas medidas das concentrações de defeitos neles induzidos por radiações ionizantes do ambiente deposicional (SHELKOPLYAS \& MOROZOV 1965, apud PRESCOTT \& ROBERTSON 1997). Os grãos minerais, como os de quartzo, recebem radiações ionizantes (partículas $\alpha$ e $\beta$ e radiação $\gamma$ ) provenientes de raios cósmicos e da desintegração de isótopos radioativos naturais, como $\mathrm{U}^{235}, \mathrm{U}^{238}$, $\mathrm{Th}^{232} \mathrm{e} \mathrm{K}^{40}$ e seus filhos radioativos, que se encontram no seu interior ou nas vizinhanças. Parte desta radiação provoca ionização por efeito fotoelétrico, produzindo defeitos pontuais ou vários tipos de centros, que resultam em aprisionamento de elétrons e lacunas. Por aquecimento do mineral até determinadas temperaturas (Termoluminescência
- TL) ou por estímulo óptico (Luminescência Opticamente Estimulada - LOE) (LIAN \& ROBERTS 2006), os elétrons aprisionados são liberados e recombinados com lacunas e emitem luminescência. Quando se mede a intensidade da luz emitida por esses centros é possível, por exemplo, determinar quando um mineral se cristalizou ou quando um sedimento foi exposto à luz solar pela última vez durante período mínimo de 6-8 horas (TL), ou até alguns minutos (LOE), segundo AITKEN (1985), ou sofreram aquecimento superior a $100{ }^{\circ} \mathrm{C}$ (AITKEN 1998).

Foram coletadas 77 amostras em afloramentos distribuídos na área de estudo (Figura 3), sendo 67 da Aloformação Paranavaí e 10 da Aloformação Paraná, para datação por TL e LOE.

As datações foram realizadas no Laboratório de Vidros e Datação (LVD) da FATEC-SP (Fa-

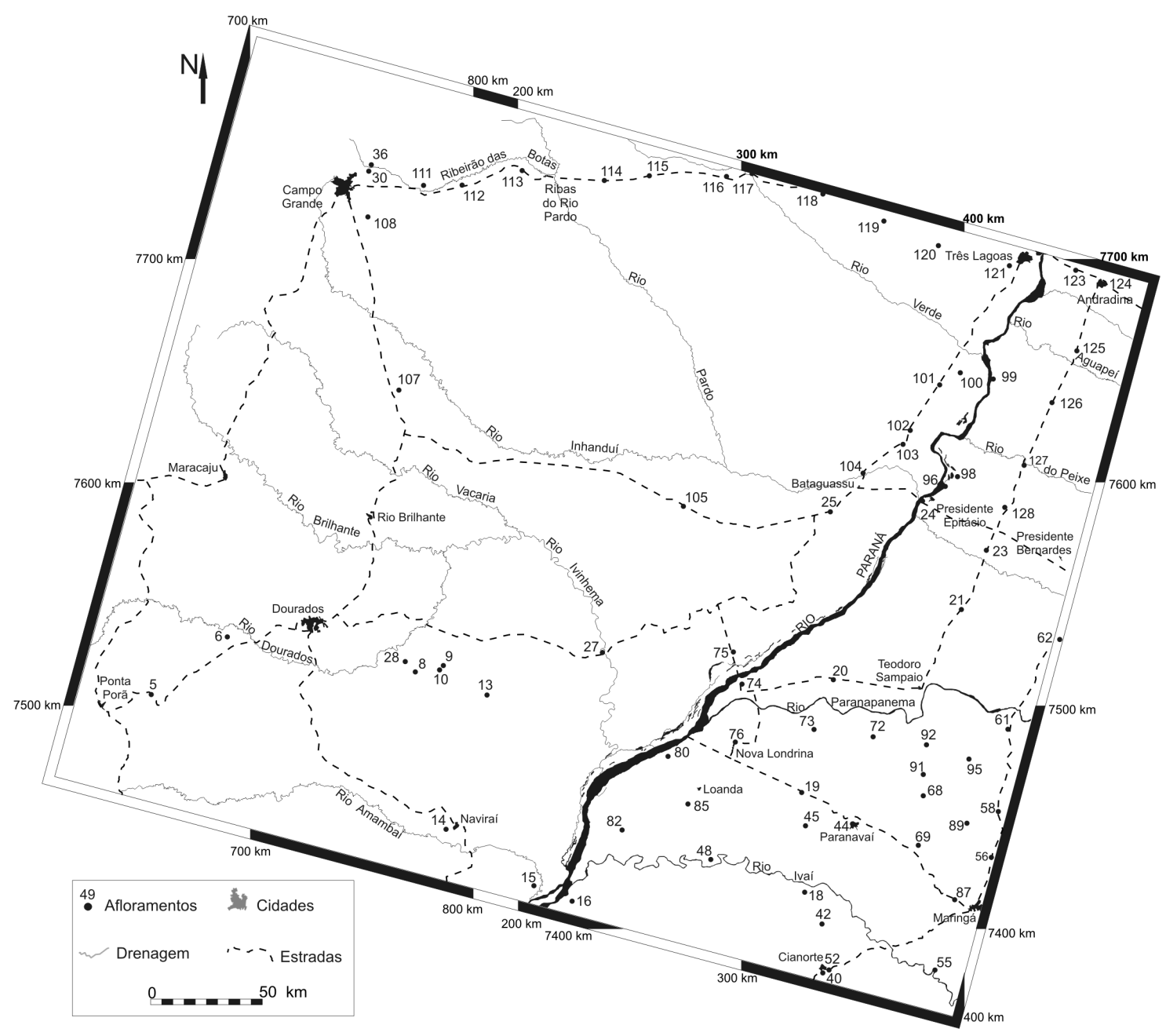

FIGURA 3 - Mapa da área de estudo com os pontos de coleta de amostras para datação por TL e LOE. 

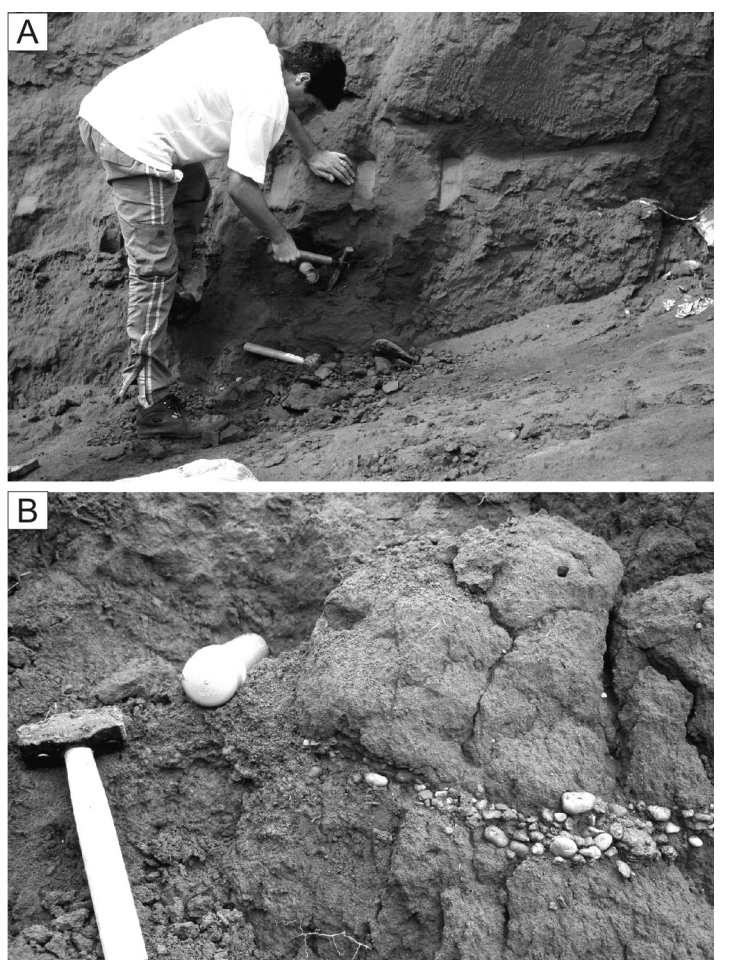

FIGURA 4 - Coleta de amostras para datação por TL e LOE: (A) Aloformação Paranavaí em Glória de Dourados (MS) no ponto 10 (UTM 784241E/7516906N); (B) Aloformação Paranavaí em Ponta Porã no ponto 5 (UTM 655422E/7504702N).

culdade de Tecnologia de São Paulo), sob coordenação da Profa. Dra. Sônia Hatsue Tatumi, com o aparelho "Automated Systems, Model 1100-series Daybreak Nuclear Instruments Inc.", com utilização de taxa de aquecimento de $10^{\circ} \mathrm{C} / \mathrm{s}$.

Para a coleta das amostras foi realizada limpeza nos afloramentos, para remoção do material superficial eventualmente caído de cima, a fim de evitar a contaminação pela incorporação de grãos minerais de diferentes idades. A coleta foi feita a, no mínimo, $0,5 \mathrm{~m}$ de profundidade em relação à superfície do terreno, para evitar materiais de exposição recente a raios solares, bem como horizontes mais bioturbados. As amostras foram coletadas em tubos opacos de PVC, introduzidos horizontalmente por percussão com uma marreta nos níveis de coleta (Figura 4). Logo após a retirada, os tubos foram fechados para evitar a exposição à radiação solar e enviados imediatamente ao laboratório para evitar o mínimo de perda de umidade.

Os sedimentos foram peneirados para separar grãos com diâmetros entre 88-180 $\mu \mathrm{m}$ (areias muito fina a fina) e submetido a tratamento quími- co. Esse tratamento foi realizado com ácidos fluorídrico (HF) e clorídrico $(\mathrm{HCl})$ concentrados para remoção de matéria orgânica, óxidos e hidróxidos de ferro e carbonatos (MEJDAHL 1979), e dissolver a porção superficial do grãos, para reduzir a contribuição das doses de partículas $\beta$ e $\alpha$. Os grãos de quartzo foram separados dos minerais pesados e feldspato com politungstato de sódio (SPT em inglês). A seguir a amostra foi separada em aproximadamente seis partes, sendo uma submetida à leitura de luminescência para obtenção da luminescência natural, e as outras cinco receberam tratamento térmico a $480^{\circ} \mathrm{C}$ por 15 minutos, para eliminar toda a TL, e foram expostas à luz solar por cerca de 16 horas, para LOE. Em seguida, cerca de $40 \mathrm{mg}$ de grãos foram enviados para o IPEN-CNEN (Instituto de Pesquisas Energéticas e Nucleares - Comissão Nacional de Energia Nuclear) para receber doses conhecidas de radiações ionizantes de ${ }^{60} \mathrm{Co}$.

As idades das amostras foram calculadas a partir da paleodose $(\mathrm{P}=$ energia total absorvida pelo cristal pela incidência de radiações ionizantes) em Gy, e das doses anuais DA (radiações- $\gamma$ ), $\mathrm{DA}_{\beta}$ (partículas- $\beta$ ) e $\mathrm{DA}_{\text {r.c. }}$ (raios cósmicos) em Gy/ano. As doses anuais foram calculadas a partir da determinação dos teores de $\mathrm{U}^{235} / \mathrm{U}^{238} \mathrm{e} \mathrm{Th}^{232} \mathrm{em}$ partes por milhão (ppm), e $\mathrm{K}^{40}$ em porcentagem $(\%)$, por espectroscopia- $\gamma$ da amostra natural sem nenhum tratamento, utilizando-se detectores de $\mathrm{NaI}(\mathrm{Tl})$. O valor de radiação cósmica utilizado foi de 174,22 $\mu$ Gy/ano (SALLUN et al. 2007b). Os valores obtidos de teores de isótopos radioativos naturais foram utilizados para possível correlação estratigráfica.

Com esses resultados foi delineada a "curva de crescimento" para cada amostra, que representa a resposta da luminescência do material à radiação (LI \& WINTLE 1992), plotando as intensidades de luminescência em função da dose. Para o cálculo das idades foram obtidos os valores das doses anuais (DAs) e das paleodoses (P), através do método da regeneração total, pela intersecção da curva de calibração com a linha que representa a luminescência natural.

\section{ISÓTOPOS RADIOATIVOS NATURAIS}

As concentrações de urânio, tório e potássio já foram usados para identificar diferentes litologias e estabelecer correlações, como em depósitos quaternários na costa sudeste (ANJOS et al. 2006), no Grupo Bambuí (ROQUE \& RIBEIRO 1997, RIBEI- 
TABELA 1 - Concentrações naturais de tório $\left({ }^{232} \mathrm{Th}\right)$ e urânio $\left({ }^{235} \mathrm{U}+{ }^{238} \mathrm{U}\right)$ em ppm (partes por milhão) e de potássio $\left({ }^{40} \mathrm{~K}\right)$ em \% (porcentagem) em amostras da Aloformação Paranavaí.

\begin{tabular}{|c|c|c|c|c|}
\hline Amostra & ${ }^{232} \mathrm{Th}(\mathrm{ppm})$ & ${ }^{235} \mathrm{U}+{ }^{238} \mathrm{U}(\mathrm{ppm})$ & ${ }^{40} \mathrm{~K}(\%)$ & ${ }^{232} \mathrm{Th} /{ }^{235} \mathrm{U}+{ }^{238} \mathrm{U}$ \\
\hline 5 & $2,20 \pm 0,065$ & $1,519 \pm 0,038$ & $0,034 \pm 0,003$ & 1,448 \\
\hline 6 & $0,309 \pm 0,009$ & $1,152 \pm 0,029$ & $0 \pm 0$ & 0,268 \\
\hline 10 (base) & $1,899 \pm 0,056$ & $1,218 \pm 0,003$ & $0,036 \pm 0,003$ & 1,559 \\
\hline 10 (topo) & $2,063 \pm 0,061$ & $1,137 \pm 0,028$ & $0,031 \pm 0,003$ & 1,814 \\
\hline 13 & $0,551 \pm 0,016$ & $1,013 \pm 0,025$ & $0 \pm 0$ & 0,544 \\
\hline 14 (base) & $0,406 \pm 0,012$ & $0,675 \pm 0,017$ & $0 \pm 0$ & 0,601 \\
\hline 14 (meio) & $0,710 \pm 0,021$ & $1,112 \pm 0,028$ & $0,071 \pm 0,007$ & 0,638 \\
\hline 14 (topo) & $0,659 \pm 0,019$ & $0,739 \pm 0,018$ & $0 \pm 0$ & 0,892 \\
\hline 16 & $0,502 \pm 0,015$ & $0,598 \pm 0,016$ & $0 \pm 0$ & 0,839 \\
\hline 18 & $3,371 \pm 0,087$ & $1,124 \pm 0,029$ & $0 \pm 0$ & 2,999 \\
\hline 19 & $1,747 \pm 0,045$ & $0,582 \pm 0,015$ & $0,022 \pm 0,002$ & 3,002 \\
\hline 20 & $2,071 \pm 0,053$ & $0,691 \pm 0,018$ & $0 \pm 0$ & 2,997 \\
\hline 21 & $5,107 \pm 0,133$ & $1,703 \pm 0,044$ & $0,014 \pm 0,001$ & 2,999 \\
\hline 23 & $3,475 \pm 0,089$ & $1,159 \pm 0,030$ & $0,011 \pm 0,001$ & 2,998 \\
\hline 25 & $4,750 \pm 0,123$ & $1,583 \pm 0,041$ & $0,014 \pm 0,001$ & 3,001 \\
\hline 28 & $3,648 \pm 0,097$ & $1,216 \pm 0,032$ & $0 \pm 0$ & 3,000 \\
\hline 30 (base) & $2,202 \pm 0,058$ & $0,734 \pm 0,020$ & $0,017 \pm 0,002$ & 3,000 \\
\hline 30 (topo) & $1,763 \pm 0,047$ & $0,588 \pm 0,016$ & $0 \pm 0$ & 3,326 \\
\hline 36 (base) & $1,672 \pm 0,042$ & $0,557 \pm 0,014$ & $0 \pm 0$ & 3,002 \\
\hline 36 (topo) & $1,995 \pm 0,049$ & $0,665 \pm 0,016$ & $0 \pm 0$ & 3,000 \\
\hline 40 (base) & $1,692 \pm 0,008$ & $0,564 \pm 0,014$ & $0,0526 \pm 0,0054$ & 3,000 \\
\hline 40 (topo) & $3,474 \pm 0,024$ & $1,158 \pm 0,029$ & $0,0177 \pm 0,0018$ & 3,000 \\
\hline 44 & $2,343 \pm 0,011$ & $0,781 \pm 0,021$ & $0 \pm 0$ & 3,000 \\
\hline 45 & $1,779 \pm 0,005$ & $0,593 \pm 0,015$ & $0 \pm 0$ & 3,000 \\
\hline 48 & $4,008 \pm 0,043$ & $1,336 \pm 0,033$ & $0,0424 \pm 0,0043$ & 3,000 \\
\hline 52 & $2,205 \pm 0,032$ & $0,735 \pm 0,018$ & $0 \pm 0$ & 3,000 \\
\hline 58 & $2,352 \pm 0,028$ & $0,784 \pm 0,020$ & $0,0439 \pm 0,0045$ & 3,000 \\
\hline 61 & $4,41 \pm 0,04$ & $1,470 \pm 0,037$ & $0 \pm 0$ & 3,000 \\
\hline 62 & $3,054 \pm 0,078$ & $1,018 \pm 0,026$ & $0 \pm 0$ & 3,000 \\
\hline 68 & $2,121 \pm 0,054$ & $0,707 \pm 0,018$ & $0 \pm 0$ & 3,000 \\
\hline 69 & $3,370 \pm 0,083$ & $1,123 \pm 0,027$ & $0 \pm 0$ & 3,001 \\
\hline 72 & $4,055 \pm 0,051$ & $1,352 \pm 0,034$ & $0 \pm 0$ & 2,999 \\
\hline 74 & $4,172 \pm 0,054$ & $1,391 \pm 0,037$ & $0 \pm 0$ & 2,999 \\
\hline 75 & $2,838 \pm 0,042$ & $0,946 \pm 0,024$ & $0 \pm 0$ & 2,999 \\
\hline 76 & $2,822 \pm 0,012$ & $0,941 \pm 0,024$ & $0 \pm 0$ & 2,999 \\
\hline 80 & $1,714 \pm 0,021$ & $0,571 \pm 0,015$ & $0,096 \pm 0,010$ & 3,000 \\
\hline 82 & $3,957 \pm 0,035$ & $1,319 \pm 0,035$ & $0 \pm 0$ & 2,999 \\
\hline 85 & $1,273 \pm 0,003$ & $0,424 \pm 0,011$ & $0 \pm 0$ & 3,002 \\
\hline 87 & $1,849 \pm 0,023$ & $0,616 \pm 0,016$ & $0 \pm 0$ & 3,000 \\
\hline 89 & $1,848 \pm 0,012$ & $0,616 \pm 0,017$ & $0 \pm 0$ & 3,002 \\
\hline 91 & $1,506 \pm 0,02$ & $0,502 \pm 0,013$ & $0,023 \pm 0,002$ & 3,002 \\
\hline 92 & $1,707 \pm 0,02$ & $0,569 \pm 0,014$ & $0,025 \pm 0,003$ & 3,000 \\
\hline 95 & $1,732 \pm 0,054$ & $0,577 \pm 0,015$ & $0 \pm 0$ & 3,000 \\
\hline 98 & $2,46 \pm 0,05$ & $0,82 \pm 0,02$ & $0,059 \pm 0,006$ & 3,000 \\
\hline 100 & $1,82 \pm 0,04$ & $0,60 \pm 0,01$ & $0 \pm 0$ & 3,002 \\
\hline 102 & $5,83 \pm 0,14$ & $1,94 \pm 0,04$ & $0,073 \pm 0,007$ & 3,000 \\
\hline 104 (base) & $2,06 \pm 0,05$ & $0,68 \pm 0,01$ & $0,009 \pm 0,0009$ & 3,033 \\
\hline 104 (topo) & $2,45 \pm 0,06$ & $0,81 \pm 0,022$ & $0,057 \pm 0,005$ & 3,005 \\
\hline 105 & $6,53 \pm 0,17$ & $2,17 \pm 0,05$ & $0,013 \pm 0,0013$ & 3,029 \\
\hline 107 & $2,58 \pm 0,067$ & $0,86 \pm 0,02$ & $0 \pm 0$ & 3,025 \\
\hline 111 & $4,07 \pm 0,09$ & $1,35 \pm 0,03$ & $0,004 \pm 0,004$ & 3,009 \\
\hline 112 & $2,94 \pm 0,07$ & $0,98 \pm 0,02$ & $0,010 \pm 0,001$ & 3,000 \\
\hline 113 & $3,38 \pm 0,08$ & $1,12 \pm 0,02$ & $0 \pm 0$ & 3,015 \\
\hline 114 & $2,27 \pm 0,05$ & $0,75 \pm 0,01$ & $0 \pm 0$ & 3,000 \\
\hline 115 & $1,77 \pm 0,04$ & $0,59 \pm 0,01$ & $0,032 \pm 0,003$ & 3,018 \\
\hline 118 & $2,68 \pm 0,06$ & $0,89 \pm 0,02$ & $0,014 \pm 0,001$ & 3,027 \\
\hline 119 & $2,72 \pm 0,06$ & $0,90 \pm 0,02$ & $0,015 \pm 0,001$ & 3,000 \\
\hline 120 & $3,46 \pm 0,008$ & $1,15 \pm 0,02$ & $0 \pm 0$ & 3,011 \\
\hline 121 & $1,0950 \pm 0,0286$ & $3,2851 \pm 0,0857$ & $0 \pm 0$ & 3,022 \\
\hline 123 & $1,2766 \pm 0,0322$ & $3,8299 \pm 0,0967$ & $0,0175 \pm 0,0018$ & 3,009 \\
\hline 124 & $1,0675 \pm 0,0271$ & $3,2026 \pm 0,0814$ & $0 \pm 0$ & 0,333 \\
\hline 125 & $0,7831 \pm 0,0210$ & $2,3492 \pm 0,0631$ & $0,0096 \pm 0,0010$ & 0,333 \\
\hline 126 & $1,1641 \pm 0,0315$ & $3,4923 \pm 0,0944$ & $0 \pm 0$ & 0,333 \\
\hline 127 & $0,3763 \pm, 0089$ & $1,1289 \pm 0,0269$ & $0,0043 \pm 0,0005$ & 0,333 \\
\hline 128 & $0,9677 \pm 0,0255$ & $2,9031 \pm 0,0766$ & $0 \pm 0$ & 0,333 \\
\hline
\end{tabular}


RO \& ROQUE 2001) e nas formações Irati e Corumbataí na Bacia do Paraná (CARLOS et al. 2004). Porém, após a sedimentação, o intemperismo, a neoformação de minerais secundários e a adsorção por argilominerais podem mudar continuamente a distribuição dos radioisótopos nos sedimentos, e indicar correlação com eventos pós-deposicionais.

\subsection{Aloformação Paranavaí}

As medições de elementos radioativos nas amostras da Aloformação Paranavaí indicam baixa concentração, com maiores teores de ${ }^{232} \mathrm{Th}(0,309$ a $6,53 \mathrm{ppm})$ do que ${ }^{235} \mathrm{U}+{ }^{238} \mathrm{U}(0,424$ a $3,82 \mathrm{ppm})$ e ${ }^{40} \mathrm{~K}(0$ a $0,096 \%)$ (Tabela 1$)$. Os estudos de possíveis correlações entre os teores dos elementos mostraram que a dispersão nos valores da razão entre ${ }^{235} \mathrm{U}+{ }^{238} \mathrm{U}$ e ${ }^{232} \mathrm{Th},(0,268$ a 3,326) permite delimitar dois grupos distintos de amostras (Figura 5A), aqui denominados de grupo $1(0,268$ a 0,333$)$ e grupo 2 $(1,448$ a 3,326$)$.

A mesma relação não foi observada entre os teores de ${ }^{232} \mathrm{Th}$ e ${ }^{235} \mathrm{U}+{ }^{238} \mathrm{U}$, em relação ao ${ }^{40} \mathrm{~K}$ (Figura 5B). No grupo 1 os teores de ${ }^{235} \mathrm{U}+{ }^{238} \mathrm{U}$ são sempre superiores aos de ${ }^{232} \mathrm{Th}$, enquanto que no grupo 2 ocorre o inverso (Figura 5C).

Quando as distribuições de ${ }^{232} \mathrm{Th},{ }^{235} \mathrm{U}+{ }^{238} \mathrm{U}$ $\mathrm{e}^{40} \mathrm{~K}$ foram analisadas na área de estudo (Figura $5 \mathrm{D}, \mathrm{E}$ e $\mathrm{F}$ ) foram encontrados maiores teores de ${ }^{232} \mathrm{Th}$ na porção central segundo a direção NW-SE, de ${ }^{235} \mathrm{U}+{ }^{238} \mathrm{U}$ na porção NE e de ${ }^{40} \mathrm{~K}$ em pontos isolados. Os grupos de amostras identificadas com as razões entre os teores de ${ }^{232} \mathrm{Th}$ e ${ }^{235} \mathrm{U}+{ }^{238} \mathrm{U}$ (Figura $5 \mathrm{G}$ ) podem ser plotados em planta; o grupo 1 localiza-se nas porções SW e NE, assim como as maiores concentrações de ${ }^{235} \mathrm{U}+{ }^{238} \mathrm{U}$, e o grupo 2, na porção central, a NW e SE da área de estudo.

Os minerais pesados geralmente apresentam altas concentrações de radionuclídeos naturais da

TABELA 2 - Concentrações naturais de tório ${ }^{232} \mathrm{Th}$ ) e urânio $\left({ }^{235} \mathrm{U}+{ }^{238} \mathrm{U}\right)$ em ppm (partes por milhão) e de potássio $\left({ }^{40} \mathrm{~K}\right)$ em \% (porcentagem) em amostras da Aloformação Paraná.

\begin{tabular}{cccc}
\hline Amostra & ${ }^{232} \mathrm{Th}(\mathrm{ppm})$ & ${ }^{235} \mathrm{U}+{ }^{238} \mathrm{U}(\mathrm{ppm})$ & ${ }^{40} \mathrm{~K}(\%)$ \\
\hline 9 & $0,455 \pm 0,013$ & $0,565 \pm 0,013$ & $0 \pm 0$ \\
15 & $2,469 \pm 0,073$ & $1,571 \pm 0,041$ & $0 \pm 0$ \\
$24-1$ & $2,386 \pm 0,057$ & $0,796 \pm 0,019$ & $0 \pm 0$ \\
$24-2$ & $0,252 \pm 0,007$ & $0,462 \pm 0,001$ & $0 \pm 0$ \\
27 & $2,951 \pm 0,074$ & $0,984 \pm 0,025$ & $0 \pm 0$ \\
96 & $4,25 \pm 0,11$ & $1,41 \pm 0,36$ & $0 \pm 0$ \\
99 & $1,41 \pm 0,03$ & $0,47 \pm 0,01$ & $0,221 \pm 0,002$ \\
103 & $2,37 \pm 0,06$ & $0,79 \pm 0,02$ & $0 \pm 0$ \\
108 & $1,05 \pm 0,026$ & $0,35 \pm 0,008$ & $0,007 \pm 0,0008$ \\
117 & $1,31 \pm 0,03$ & $0,43 \pm 0,01$ & $0 \pm 0$ \\
\hline
\end{tabular}

série de decaimento de urânio e tório em sua estrutura cristalina (ANJOS et al. 2006). Porém, as concentrações de ${ }^{232} \mathrm{Th}$ e ${ }^{235} \mathrm{U}+{ }^{238} \mathrm{U}$ nos minerais pesados das distribuições areias fina e muito fina nas amostras estudadas não mostraram esta tendência (Figura 5H e I).

Os minerais leves, como quartzo e feldspato, contêm em geral teores muito baixos de urânio e tório, embora o feldspato possa conter ${ }^{40} \mathrm{~K}$. Porém, em nenhuma amostra com feldspato foi identificada qualquer concentração de ${ }^{40} \mathrm{~K}$. Finalmente, não foi verificada correlação entre os teores de ${ }^{232} \mathrm{Th} \mathrm{e}^{235} \mathrm{U}+{ }^{238} \mathrm{U}$ e os conteúdos de fração fina (silte e argila) na massa total de sedimento (Figura 5J), e também com as idades obtidas por TL ou LOE (Figura $5 \mathrm{~K} \mathrm{e} \mathrm{L}$ ).

\subsection{Aloformação Paraná}

As medidas de elementos radioativos nas amostras da Aloformação Paraná também indicam baixa concentração, com maiores teores de ${ }^{232} \mathrm{Th}$ $(0,252$ a 4,25 ppm $)$ do que ${ }^{235} \mathrm{U}+{ }^{238} \mathrm{U}(0,35$ a 1,571 ppm) e ${ }^{40} \mathrm{~K}(0$ a $0,221 \%)$ (Tabela 2$)$. As possíveis correlações entre os teores dos elementos indicaram que a dispersão nos valores da razão entre ${ }^{235} \mathrm{U}+{ }^{238} \mathrm{U}$ e ${ }^{232} \mathrm{Th}(0,545$ a 3,046$)$ é correlacionável aos grupos identificados na Aloformação Paranavaí (Figura 5A). Apesar da menor quantidade de amostras analisadas da Aloformação Paraná, é ainda possível reconhecer os grupos $1(0,252$ a $0,455)$ e $2(1,05$ a 4,25) da Aloformação Paranavaí (Figura 6A). Não há relação entre os teores de ${ }^{232} \mathrm{Th}$ e ${ }^{235} \mathrm{U}+{ }^{238} \mathrm{U}$ e os de ${ }^{40} \mathrm{~K}$ (Figura 6B). No grupo 1 os teores de ${ }^{235} \mathrm{U}+{ }^{238} \mathrm{U}$ são sempre superiores aos de ${ }^{232} \mathrm{Th}$, enquanto que no grupo 2 ocorre o inverso (Figura 6C).

Quando as distribuições de ${ }^{232} \mathrm{Th},{ }^{235} \mathrm{U}+{ }^{238} \mathrm{U}$ $\mathrm{e}^{40} \mathrm{~K}$ são analisadas na área de estudo, constatamse correlações entre as aloformações Paranavaí e Paraná nos grupos 1 e 2 , em teores de ${ }^{232} \mathrm{Th}$, ${ }^{235} \mathrm{U}+{ }^{238} \mathrm{U}$ e nos baixos conteúdos de ${ }^{40} \mathrm{~K}$.

Nenhuma correlação aparente foi detectada entre os teores de ${ }^{232} \mathrm{Th}$ e ${ }^{235} \mathrm{U}+{ }^{238} \mathrm{U}$ e os conteúdos de fração fina (silte e argila) na massa total de sedimento (Figura 6D), e também com as idades obtidas por TL ou LOE (Figura 6E e F).

\section{DATAÇÕES POR LUMINESCÊNCIA}

\subsection{Aloformação Paranavaí}

Os sinais de luminescência da maioria das amostras analisadas apresentaram "curvas de cres- 

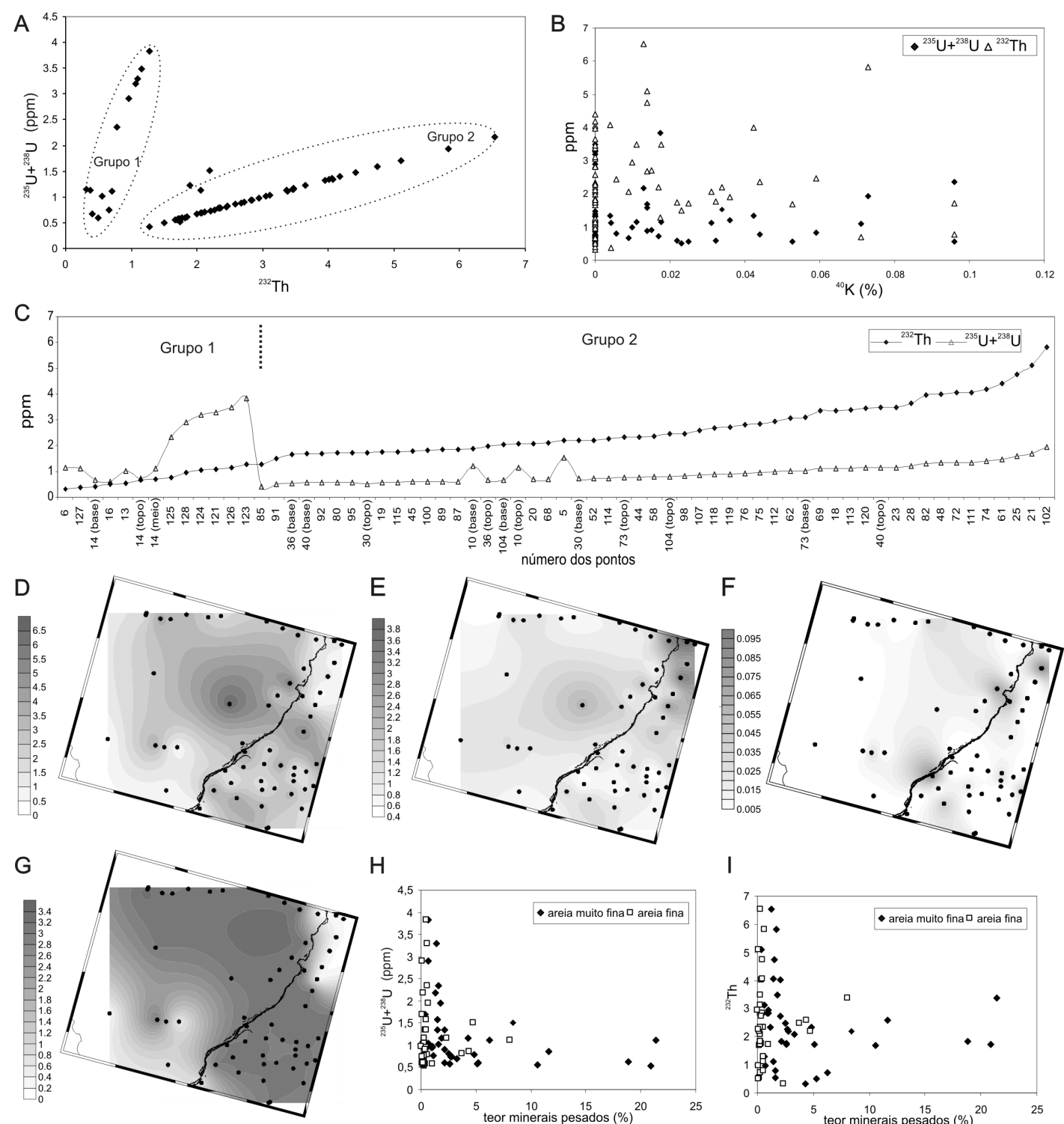

J

K
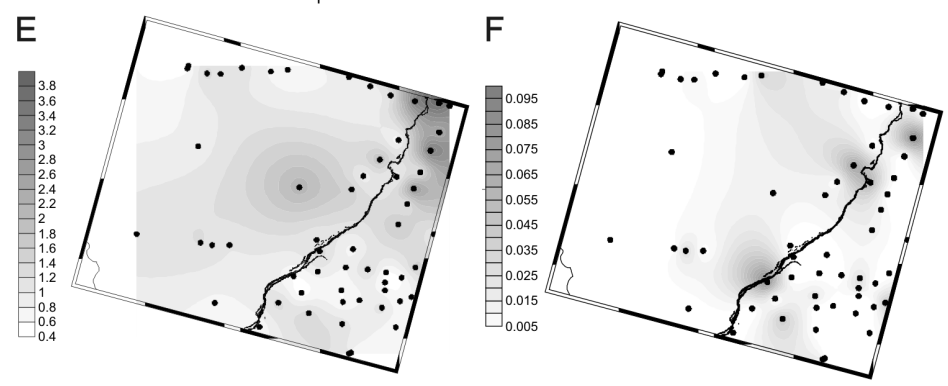

I
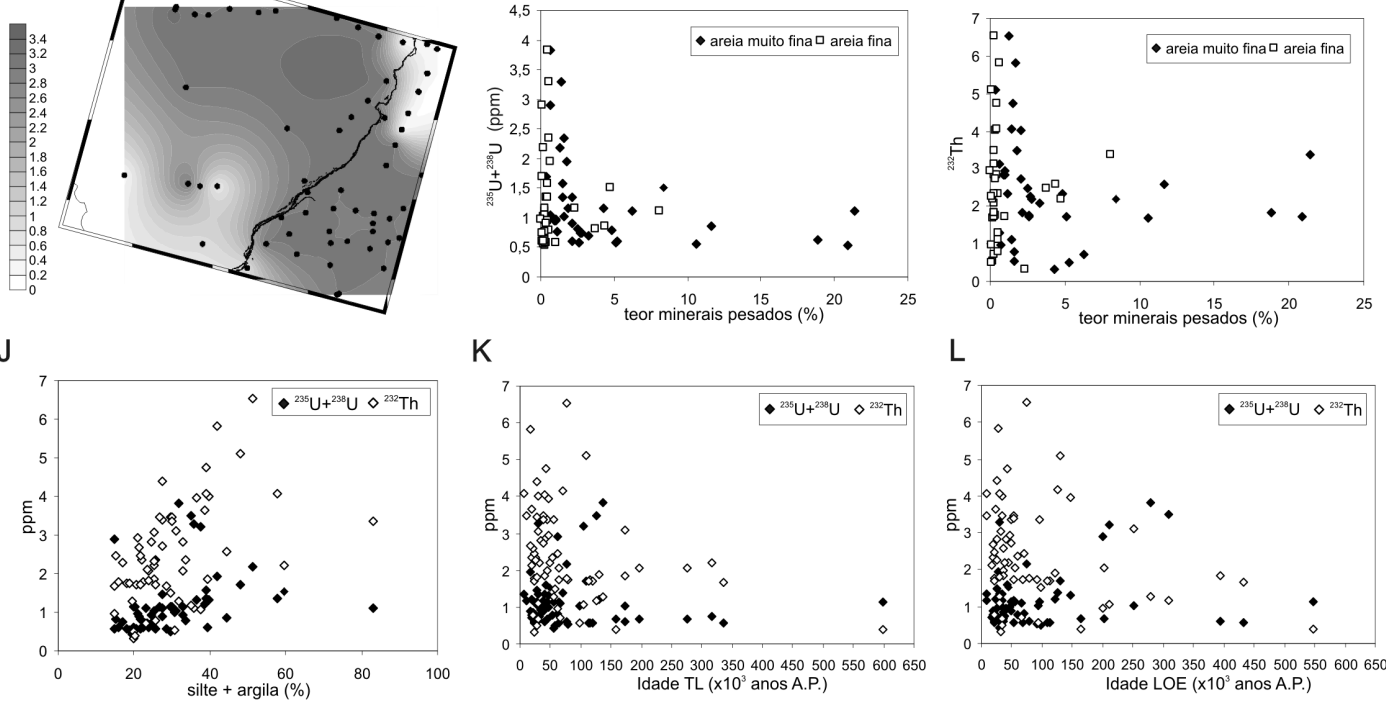

L

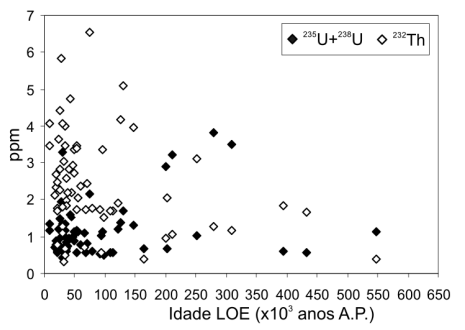

FIGURA 5 - Distribuição dos dados de isótopos radioativos de ${ }^{232} \mathrm{Th}$ e ${ }^{235} \mathrm{U}+{ }^{238} \mathrm{U}$ em ppm (partes por milhão) e ${ }^{40} \mathrm{~K}$ em \% (porcentagem) nas amostras analisadas da Aloformação Paranavaí. Diferentes grupos de amostras identificados em gráficos de dispersão de teores de ${ }^{232} \mathrm{Th}$ e ${ }^{235} \mathrm{U}+{ }^{238} \mathrm{U}$ (grupos 1 e 2) (A) e de ${ }^{232} \mathrm{Th}$ e ${ }^{235} \mathrm{U}+{ }^{238} \mathrm{U}$ em relação a ${ }^{40} \mathrm{~K}$ (B). Distribuição dos teores de ${ }^{232} \mathrm{Th}$ e ${ }^{235} \mathrm{U}+{ }^{238} \mathrm{U}$ (C); Distribuição na área de estudo de ${ }^{232} \mathrm{Th}$ (D), ${ }^{235} \mathrm{U}+{ }^{238} \mathrm{U}(\mathrm{E}) \mathrm{e}{ }^{40} \mathrm{~K}(\mathrm{~F})$ e da razão entre os teores ${ }^{232} \mathrm{Th}$ e ${ }^{235} \mathrm{U}+{ }^{238} \mathrm{U}(\mathrm{G})$; Dispersão de teores de ${ }^{235} \mathrm{U}+{ }^{238} \mathrm{U}$ (H) e de ${ }^{232} \mathrm{Th}$ (I) em relação ao teor de minerais pesados (\% em peso) nas distribuições areia fina e muito fina, de ${ }^{232} \mathrm{Th}$ e ${ }^{235} \mathrm{U}+{ }^{238} \mathrm{U}$ em relação ao conteúdo da fração fina (silte e argila) na massa total de sedimento $(\mathrm{J})$ e em relação às idades obtidas por TL $(\mathrm{K})$ e por LOE $(\mathrm{L})$. 
A

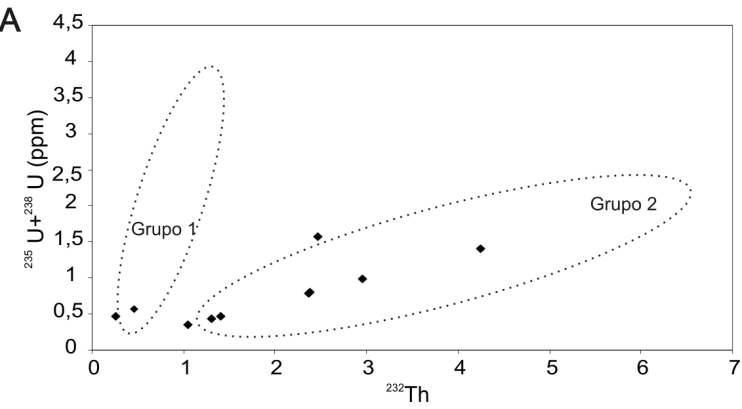

C

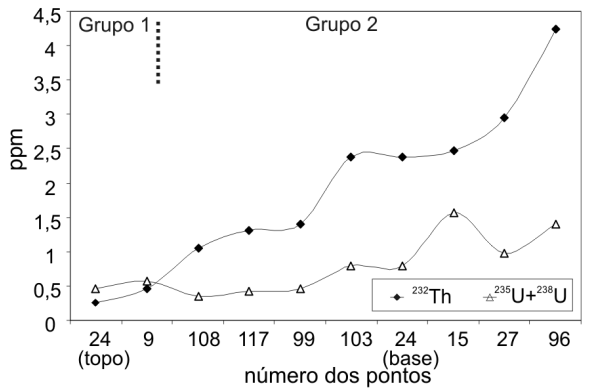

$\mathrm{E}$

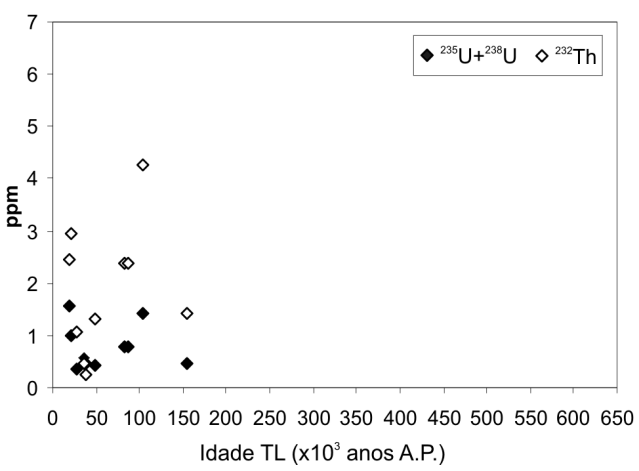

B

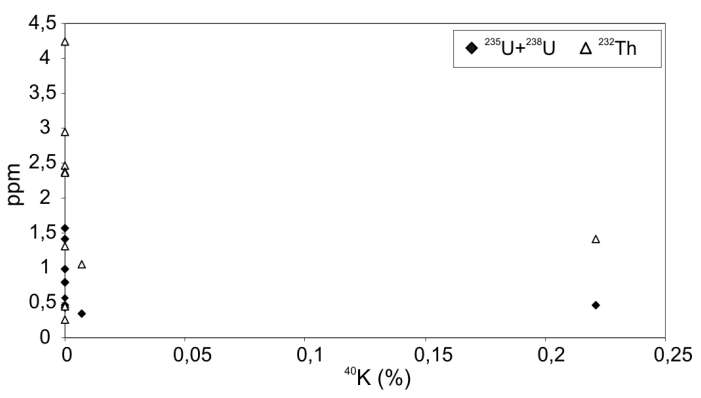

D

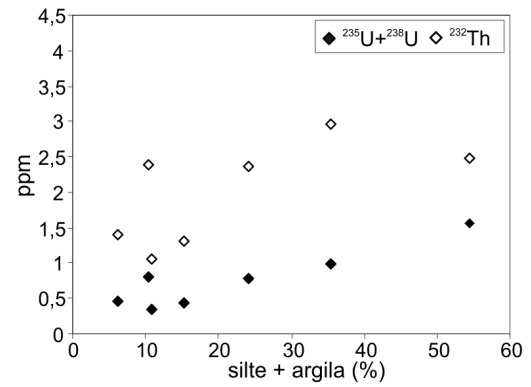

$\mathrm{F}$

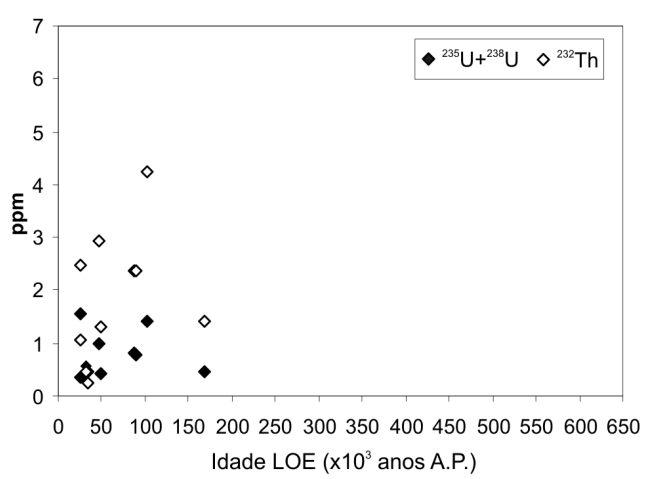

FIGURA 6 - Distribuição dos dados de isótopos radioativos de ${ }^{232} \mathrm{Th}$ e ${ }^{235} \mathrm{U}+{ }^{238} \mathrm{U}$ em ppm (partes por milhão) e ${ }^{40} \mathrm{~K}$ em \% (porcentagem) nas amostras analisadas da Aloformação Paraná. Diferentes grupos de amostras identificados em gráfico de dispersão de teores de ${ }^{232} \mathrm{Th}$ e ${ }^{235} \mathrm{U}+{ }^{238} \mathrm{U}(\mathrm{ppm})$, denominados grupos 1 e 2 (A); Dispersão de teores de ${ }^{232} \mathrm{Th}$ e ${ }^{235} \mathrm{U}+{ }^{238} \mathrm{U}$ (ppm) em relação a ${ }^{40} \mathrm{~K}$ (\%) (B); Distribuição dos teores de ${ }^{232} \mathrm{Th}$ e ${ }^{235} \mathrm{U}+{ }^{238} \mathrm{U}$ (ppm) nas amostras estudadas, com indicação dos grupos 1 e 2 (C); Dispersão de teores de ${ }^{232} \mathrm{Th}$ e ${ }^{235} \mathrm{U}+{ }^{238} \mathrm{U}$ (ppm) em relação ao conteúdo da fração fina (silte e argila) na massa total de sedimento (D) e em relação às idades obtidas por TL (E) e LOE (F).

cimento" lineares para TL e LOE (Figura 7A) e as idades obtidas podem ser consideradas confiáveis (Tabela 3).

Algumas amostras apresentaram idades TL e LOE discrepantes, isto é, TL menor que LOE, quando foram identificados os seguintes problemas relacionados ao método LOE:

a) Desvio padrão muito alto nos dados de luminescência natural com LOE: ocorreu nas amostras dos pontos 23, 25, 28, 30 (topo), 69, 73 (topo), 75, 82, 87, 92, 102, 104 (topo), 107, $112,113,119,121,123,124,125$ e 126 . A dispersão dos sinais de luminescência sugere que o sedimento não teria sido exposto à luz solar por tempo suficientemente longo, isto é, provavelmente teria ocorrido deposição muito rápida, como também verificado na Namíbia por SRIVASTAVA et al. (2006).

Para diminuir o desvio padrão, medidas adicionais de luminescência natural foram repetidas 19 vezes, embora em geral 5 medidas sejam consideradas suficientes. Após este procedimento as idades por LOE e TL, das amostras provenientes dos pontos 69, 73 (topo), 112, 121 e 125, indicaram valores semelhantes e houve diminuição do desvio padrão. Essas amostras não apresentam nenhuma 
TABELA 3 - Idades absolutas em x $10^{3}$ anos A.P. obtidas por métodos TL e LOE em amostras da Formação Paranavaí ( $\mathrm{P}=$ paleodose e $\mathrm{Da}=$ dose anual).

\begin{tabular}{|c|c|c|c|c|c|}
\hline Amostra & $\mathrm{Da}(\mu \mathrm{Gy} / \mathrm{yr})$ & P-TL (Gy) & P-LOE (Gy) & Idade TL & Idade LOE \\
\hline 5 & $943 \pm 22$ & 46,10 & 42,50 & $48,8 \pm 6$ & $45 \pm 5,5$ \\
\hline 6 & $593 \pm 10$ & 14,50 & 18,81 & $24,5 \pm 2,8$ & $31,7 \pm 3,7$ \\
\hline 10 (base) & $800 \pm 19$ & 104,00 & 97,9 & $130 \pm 16$ & $122 \pm 15$ \\
\hline 10 (topo) & $755 \pm 17$ & 48,90 & 42,18 & $64,7 \pm 7,9$ & $55,8 \pm 6,8$ \\
\hline 13 & $663 \pm 12$ & 64,70 & 62,0 & $97,5 \pm 11,5$ & $93,4 \pm 11$ \\
\hline 14 (base) & $500 \pm 9$ & 79,40 & 82,39 & $158 \pm 18,5$ & $164 \pm 19$ \\
\hline 14 (meio) & $785 \pm 21$ & 51,35 & 52,68 & $65,4 \pm 8,3$ & $67 \pm 8,5$ \\
\hline 14 (topo) & $531 \pm 9$ & 16,20 & 18,13 & $30,5 \pm 3,5$ & $34 \pm 4$ \\
\hline 16 & $463 \pm 8$ & 13,25 & 15,49 & $28,6 \pm 3,3$ & $33,4 \pm 3,9$ \\
\hline 18 & $717 \pm 14$ & 32 & 69 & $44,6 \pm 5,1$ & $96,2 \pm 11,1$ \\
\hline 19 & $478 \pm 14$ & 55 & 33 & $115 \pm 13,2$ & $69 \pm 7,9$ \\
\hline 20 & $508 \pm 9$ & 140 & 343 & $275,6 \pm 31,7$ & $675,2 \pm 77,7$ \\
\hline 21 & $1010 \pm 23$ & 166 & 198 & $109,4 \pm 12,6$ & $130,4 \pm 15$ \\
\hline 23 & $745 \pm 15$ & 28 & 39 & $37,6 \pm 4,3$ & $52,4 \pm 6$ \\
\hline 25 & $953 \pm 21$ & 41 & 41 & $43 \pm 5$ & $43 \pm 5$ \\
\hline 28 & $761 \pm 16$ & 14 & 18 & $18,4 \pm 2,1$ & $23,7 \pm 2,7$ \\
\hline 30 (base) & $546 \pm 11$ & 173 & - & $316,9 \pm 36,4$ & - \\
\hline 30 (topo) & $458 \pm 8$ & 36 & 42 & $78,6 \pm 9$ & $91,7 \pm 10,5$ \\
\hline 36 (base) & $443 \pm 7$ & 149 & 192 & $336,3 \pm 38,7$ & $433,4 \pm 49,8$ \\
\hline 36 (topo) & $495 \pm 8$ & 22 & 18 & $44,4 \pm 5,1$ & $36,4 \pm 4,2$ \\
\hline 40 (base) & $501 \pm 10$ & 60,30 & 57,19 & $120 \pm 14$ & $114 \pm 13,5$ \\
\hline 40 (topo) & $752 \pm 11$ & 8,20 & 6,9 & $10,9 \pm 1,2$ & $9 \pm 1$ \\
\hline 44 & $551 \pm 6$ & 14,72 & 12,02 & $26,7 \pm 2,9$ & $21,8 \pm 2,4$ \\
\hline 45 & $461 \pm 4$ & 10,85 & 9,78 & $23,5 \pm 2,5$ & $21,2 \pm 2,3$ \\
\hline 48 & $863 \pm 16$ & 26,0 & 29,14 & $30 \pm 3,5$ & $33,7 \pm 4$ \\
\hline 52 & $529 \pm 7$ & 17,48 & 15,95 & $33 \pm 3,7$ & $37,7 \pm 4,2$ \\
\hline 58 & $598 \pm 12$ & 32,17 & 35,76 & $53,7 \pm 6,4$ & $59,8 \pm 7$ \\
\hline 61 & $884 \pm 13$ & 24,98 & 23,02 & $28,2 \pm 3,2$ & $26 \pm 2,9$ \\
\hline 62 & $666 \pm 13$ & 20,15 & 21,93 & $30,2 \pm 3,6$ & $33 \pm 4$ \\
\hline 68 & $516 \pm 9$ & 9,55 & 9,05 & $18,5 \pm 2$ & $17,5 \pm 2$ \\
\hline 69 & $717 \pm 13$ & 39,75 & 35,94 & $55,4 \pm 6,5$ & $50 \pm 6$ \\
\hline 72 & $827 \pm 16$ & 33 & 25 & $39,9 \pm 4,6$ & $30,2 \pm 3,5$ \\
\hline 73 (base) & $674 \pm 12$ & 117 & 169 & $173,6 \pm 20$ & $250,7 \pm 28,8$ \\
\hline 73 (topo) & $549 \pm 10$ & 10 & 11 & $18,2 \pm 2,1$ & $20 \pm 2,3$ \\
\hline 74 & $846 \pm 18$ & 59 & 106 & $69,7 \pm 8$ & $125,3 \pm 14,4$ \\
\hline 75 & $628 \pm 12$ & 25 & 26 & $39,6 \pm 4,6$ & $41,2 \pm 4,7$ \\
\hline 76 & $628 \pm 12$ & 22 & 16 & $35 \pm 4$ & $25,5 \pm 2,9$ \\
\hline 80 & $548 \pm 18$ & 62 & 60 & $113,1 \pm 13$ & $109,5 \pm 12,6$ \\
\hline 82 & $811 \pm 17$ & 38 & 119 & $46,9 \pm 5,4$ & $146,7 \pm 16,9$ \\
\hline 85 & $379 \pm 5$ & 21 & 11 & $55,4 \pm 6,4$ & $29 \pm 3,3$ \\
\hline 87 & $472 \pm 8$ & 82 & 186 & $173,7 \pm 20$ & $394,1 \pm 45,3$ \\
\hline 89 & $472 \pm 8$ & 19 & 17 & $40,3 \pm 4,6$ & $36 \pm 4,1$ \\
\hline 91 & $440 \pm 9$ & 25 & 43 & $56,8 \pm 6,5$ & $97,7 \pm 11,2$ \\
\hline 92 & $475 \pm 9$ & 11 & 10 & $23,2 \pm 2,7$ & $21,1 \pm 2,4$ \\
\hline 95 & $453 \pm 7$ & 29 & 24 & $64 \pm 7,4$ & $53 \pm 6,1$ \\
\hline 98 & $632 \pm 16$ & 14,7 & 12,95 & $23 \pm 2,9$ & $20,5 \pm 2,5$ \\
\hline 100 & $467 \pm 7$ & 12,74 & 13,76 & $27 \pm 3$ & $29 \pm 3,5$ \\
\hline 102 & $1.188 \pm 32$ & 20,16 & 32,20 & $17 \pm 2$ & $27 \pm 3,4$ \\
\hline 104 (base) & $517 \pm 10$ & 101,4 & 105 & $196 \pm 22$ & $203 \pm 24$ \\
\hline 104 (topo) & $616 \pm 17$ & 38,59 & 43,9 & $61 \pm 7,5$ & $71 \pm 9$ \\
\hline 105 & $1.420 \pm 29$ & 95,37 & 91,4 & $76,8 \pm 9,5$ & $73,6 \pm 9$ \\
\hline 107 & $591 \pm 11$ & 13,2 & 21,8 & $22,3 \pm 2,5$ & $36,3 \pm 4,3$ \\
\hline 111 & $835 \pm 16$ & 5,2 & 6,4 & $6,2 \pm 0,75$ & $7,6 \pm 0,9$ \\
\hline 112 & $660 \pm 13$ & 31,0 & 41,0 & $46,9 \pm 5,6$ & $46,9 \pm 5,6$ \\
\hline 113 & $716 \pm 13$ & 28,20 & 39 & $39,2 \pm 4,5$ & $54,2 \pm 6,4$ \\
\hline 114 & $541 \pm 9$ & 13,36 & 13,71 & $24,7 \pm 2,8$ & $25 \pm 3$ \\
\hline 115 & $493 \pm 10$ & 38,25 & 38,78 & $77,5 \pm 9,5$ & $78,5 \pm 9,5$ \\
\hline 118 & $622 \pm 12$ & 10,16 & 12,37 & $16,3 \pm 2$ & $19,5 \pm 2,3$ \\
\hline 119 & $630 \pm 13$ & 24,64 & 21,74 & $39 \pm 4,5$ & $50 \pm 6$ \\
\hline 120 & $732 \pm 14$ & 20,31 & 24,51 & $27,5 \pm 3,3$ & $33,5 \pm 4$ \\
\hline 121 & $779 \pm 14$ & 23 & 24 & $29,5 \pm 3,4$ & $30,8 \pm 3,5$ \\
\hline 123 & $885 \pm 17$ & 58 & 247 & $136,7 \pm 15,7$ & $279,1 \pm 32,1$ \\
\hline 124 & $766 \pm 13$ & 80 & 162 & $104,4 \pm 12$ & $211,5 \pm 24,3$ \\
\hline 125 & $638 \pm 11$ & 14 & 14 & $21,9 \pm 2,5$ & $21,9 \pm 2,5$ \\
\hline 126 & $812 \pm 15$ & 103 & 251 & $126,9 \pm 14,6$ & $309,1 \pm 35,6$ \\
\hline 127 & $436 \pm 5$ & 261 & 239 & $598,6 \pm 68,8$ & $548,2 \pm 63$ \\
\hline 128 & $717 \pm 12$ & 44 & 144 & $61,4 \pm 7,1$ & $200,8 \pm 23,1$ \\
\hline
\end{tabular}


TABELA 4 - Idades mínima e máxima em x $10^{3}$ anos A.P. obtidas por LOE em amostras da Aloformação Paranavaí $(\mathrm{P}=$ paleodose e $\mathrm{Da}=$ dose anual) que não tiveram o sinal de luminescência "zerado" durante sua deposição, além da diferença mínima entre as idades por LOE e TL.

\begin{tabular}{cccccccc}
\hline Amostra & $\begin{array}{c}\mathrm{Da} \\
(\mu \mathrm{Gy} / \mathrm{yr})\end{array}$ & $\begin{array}{c}\text { P-LOE } \\
(\mathrm{Gy}) \text { mínimo }\end{array}$ & $\begin{array}{c}\text { P-LOE } \\
(\mathrm{Gy}) \text { máximo }\end{array}$ & $\begin{array}{c}\text { LOE } \\
\text { mínimo }\end{array}$ & $\begin{array}{c}\text { LOE } \\
\text { máximo }\end{array}$ & Idade TL & $\begin{array}{c}\text { \# mínima } \\
(\mathrm{LOE}-\mathrm{TL})\end{array}$ \\
\hline 23 & $745 \pm 15$ & 39 & 61 & $52,4 \pm 6$ & $81,9 \pm 9,3$ & $37,6 \pm 4,3$ & 4,5 \\
25 & $953 \pm 21$ & 41 & 54 & $43 \pm 5$ & $56,7 \pm 6,5$ & $43 \pm 5$ & - \\
28 & $761 \pm 16$ & 18 & 26 & $23,7 \pm 4,7$ & $34,2 \pm 3,9$ & $18,4 \pm 2,1$ & - \\
30 (topo) & $458 \pm 8$ & 42 & 85 & $91,7 \pm 10,5$ & $185,6 \pm 21,2$ & $78,6 \pm 9$ & - \\
75 & $631 \pm 12$ & 26 & 40 & $41,2 \pm 4,7$ & $63,4 \pm 7,2$ & $39,6 \pm 4,6$ & - \\
82 & $811 \pm 17$ & 119 & 152 & $146,7 \pm 16,9$ & $187,4 \pm 21,4$ & $46,9 \pm 5,4$ & 77,5 \\
87 & $472 \pm 8$ & 186 & 366 & $394,1 \pm 45,3$ & $775,4 \pm 88,4$ & $173,7 \pm 20$ & 155,1 \\
92 & $475 \pm 9$ & 10 & 22 & $21,1 \pm 2,4$ & $46,3 \pm 5,3$ & $23,2 \pm 2,7$ & - \\
102 & $1.188 \pm 32$ & 33,2 & 44,8 & $27 \pm 3,4$ & $37,7 \pm 4,7$ & $17 \pm 2$ & 4,6 \\
104 (topo) & $616 \pm 17$ & 43,9 & 75,7 & $71 \pm 9$ & $120 \pm 15$ & $61 \pm 7,5$ & - \\
107 & $591 \pm 11$ & 21,8 & 31,2 & $36,3 \pm 4,3$ & $52 \pm 6,2$ & $22,3 \pm 2,5$ & 7,2 \\
113 & $716 \pm 13$ & 39 & 51,6 & $54,2 \pm 6,4$ & $71,8 \pm 8,5$ & $39,2 \pm 4,5$ & 4,1 \\
119 & $630 \pm 13$ & 24,64 & 33,5 & $50 \pm 6$ & $53 \pm 6,5$ & $39 \pm 4,5$ & 0,5 \\
123 & $885 \pm 17$ & 247 & 370 & $279,1 \pm 32,1$ & $418,1 \pm 47,7$ & $136,7 \pm 15,7$ & 120,3 \\
124 & $766 \pm 13$ & 162 & 371 & $211,5 \pm 24,3$ & $484,3 \pm 55,2$ & $104,4 \pm 12$ & 70,8 \\
126 & $812 \pm 15$ & 251 & 351 & $309,1 \pm 35,6$ & $432,3 \pm 49,3$ & $21,9 \pm 2,5$ & 249,1 \\
\hline
\end{tabular}

TABELA 5 - Idades obtidas (x10 anos A.P.) das datações por TL e LOE de amostras da Aloformação Paraná $(\mathrm{P}=$ paleodose $)$.

\begin{tabular}{cccccc}
\hline Amostra & Da $(\mu \mathrm{Gy} / \mathrm{yr})$ & P-TL $(\mathrm{Gy})$ & P-LOE $(\mathrm{Gy})$ & Idade TL & Idade LOE \\
\hline 9 & $446 \pm 7$ & 16,2 & 14,5 & $36 \pm 4,1$ & $32 \pm 3,7$ \\
15 & $933 \pm 20$ & 18,6 & 24,00 & $20 \pm 2,4$ & $25 \pm 3$ \\
24 (base) & $558 \pm 9$ & 46 & 49 & $82,4 \pm 9,5$ & $87,8 \pm 10,1$ \\
24 (topo) & $397 \pm 6$ & 15,3 & 13,5 & $38,5 \pm 4,4$ & $34 \pm 3,9$ \\
27 & $649 \pm 12$ & 14 & 31 & $21,6 \pm 2,5$ & $47,8 \pm 5,5$ \\
96 & $859 \pm 18$ & 88,64 & 88,43 & $103 \pm 12,5$ & $102 \pm 12,5$ \\
99 & $424 \pm 8$ & 49,65 & 71,40 & $155 \pm 18$ & $168 \pm 20$ \\
103 & $556 \pm 10$ & 48,50 & 50,40 & $87 \pm 10$ & $90,5 \pm 10$ \\
108 & $352 \pm 5$ & 9,59 & 9,11 & $27,2 \pm 3,1$ & $25,8 \pm 3$ \\
117 & $386 \pm 5$ & 18,78 & 19,34 & $48,5 \pm 5$ & $50 \pm 5,7$ \\
\hline
\end{tabular}

anomalia nos teores de urânio, tório ou potássio, quando comparados aos de outras amostras da área de estudo.

As idades das amostras coletadas nos pontos 23, 25, 28, 30 (topo), 75, 82, 87, 92, 102, 104 (topo), 107, 113, 119, 123, 124 e 126 apresentaram idades diferentes por TL e LOE, mesmo após as medidas adicionais; as idades por LOE sempre são maiores que as obtidas por TL. Isto sugere que os grãos de quartzo tenham sido expostos heterogeneamente à luz solar, isto é, alguns grãos teriam sido "zerados" e outros não à LOE. A idade aparente representaria o valor médio de LOE de todos os grãos, que sempre tende a ser maior que a idade da última exposição solar.

Em cada uma dessas amostras heterogêneas por LOE foram obtidas idades mínima e máxima (Tabela 4), que provavelmente refletem a idade máxima residual do ciclo deposicional anterior e a idade mínima do último ciclo deposicional (Figura 7B). As idades mínimas de algumas amostras são comparáveis às idades TL (pontos $25,28,30$ topo, 75 e 92), mas estas sempre são mais confiáveis por não terem apresentado nenhuma anomalia ou dispersão de sinais de luminescência.

b) Desvio padrão normal nos dados de luminescência natural com LOE: verificado nas amostras dos pontos 18,19, 20, 21, 27, 36 (topo), 30 (base), 36 (base), 73 (base), 74, 76, 85, 91 e 128. A LOE dos grãos de quartzo parece ter decaído muito lentamente com a exposição à luz solar, provavelmente em função de alguma anomalia cristalográfica não identificada neste estudo.

\subsection{Aloformação Paraná}

Os sinais de luminescência da maioria das amostras analisadas apresentaram "curvas de crescimento" lineares de TL e LOE e, portanto, as idades foram consideradas confiáveis (Tabela 5).

Algumas amostras apresentaram discrepâncias entre os métodos TL e LOE, com idades 
A

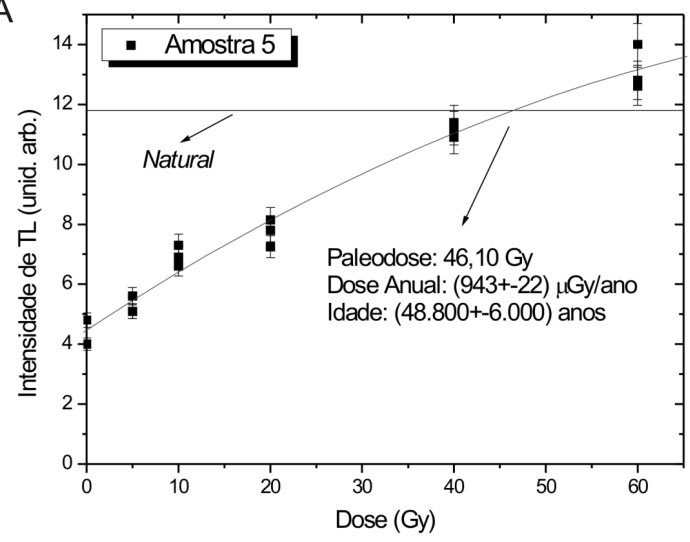

B

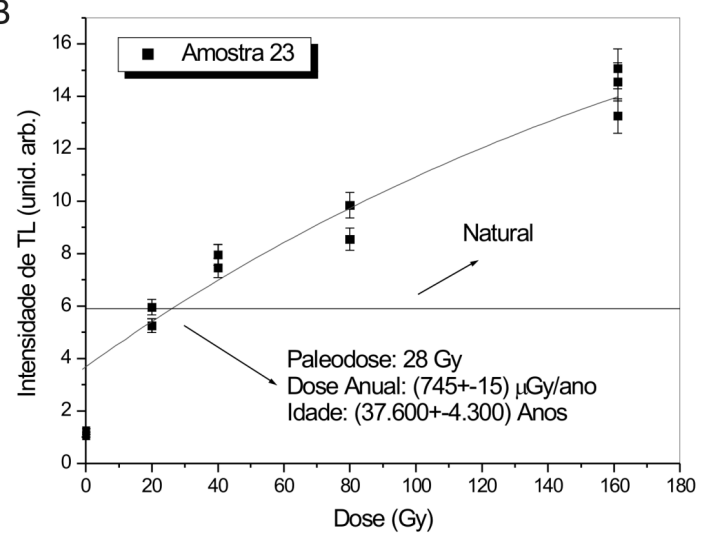

C

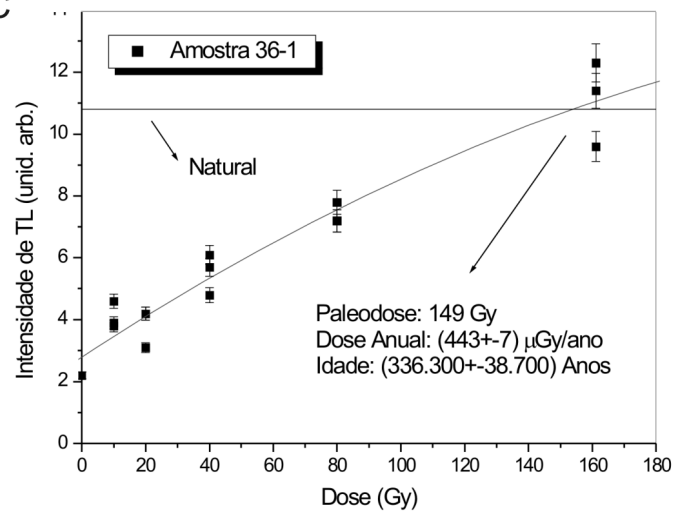

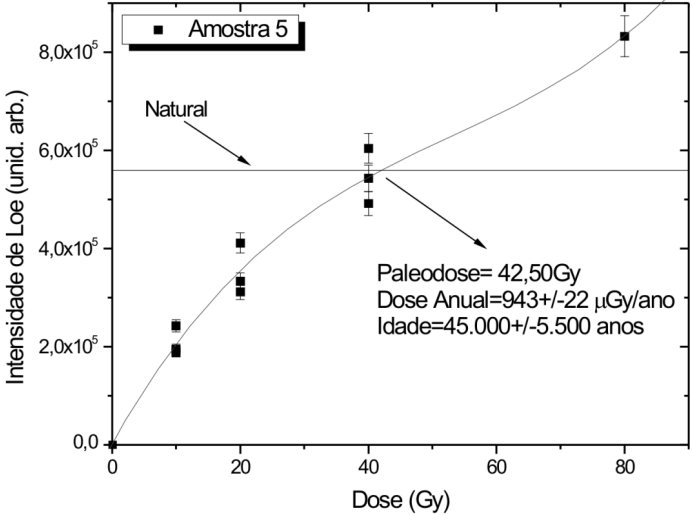
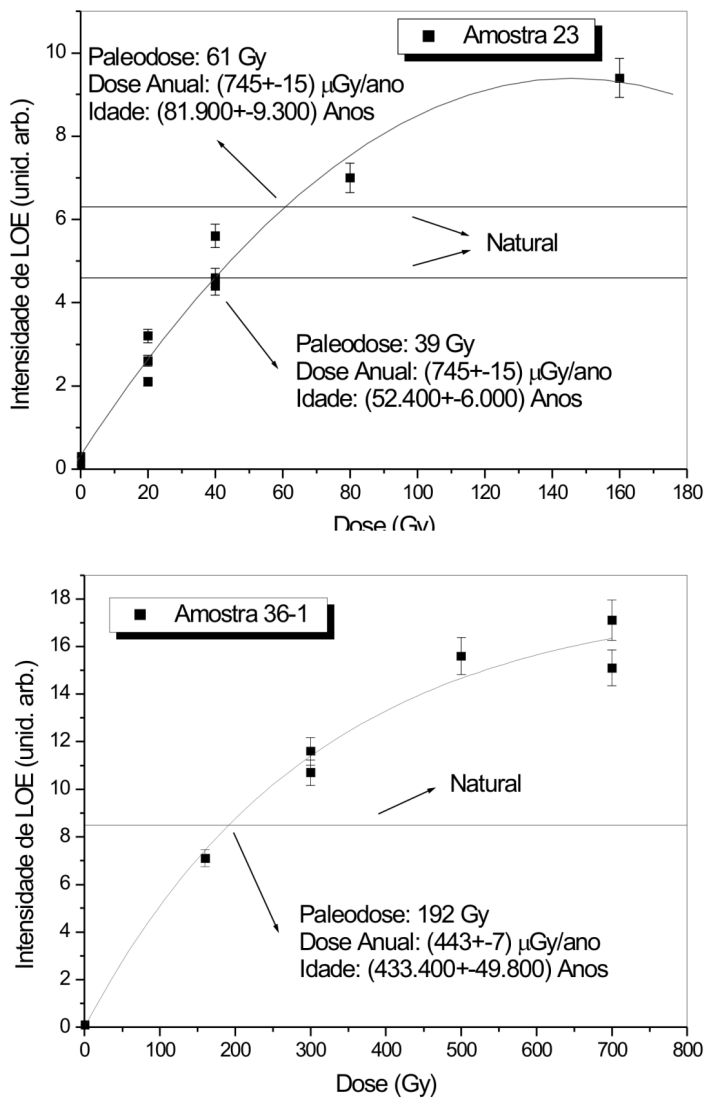

FIGURA 7 - Exemplos de curvas de calibração de grãos de quartzo pelo método da regeneração total, à temperatura em torno de $375^{\circ} \mathrm{C}$, de amostras da Aloformação Paranavaí. (A) Gráficos de curvas de crescimento linear para TL e LOE (amostra do ponto 5); (B) Gráficos de curvas de crescimento onde se observam idades incompatíveis para TL e LOE, com destaque para as idades mínima e máxima dos grãos de quartzo por LOE (amostra do ponto 23); (C) Gráficos de curvas de crescimento onde se observa idades incompatíveis para TL e LOE, por problema microscópico cristalográfico dos grãos de quartzo por LOE (amostra do ponto 36-1=base do perfil).

TL menores do que as obtidas por LOE, e nessas amostras foram identificados os seguintes problemas associados ao método LOE:

a) Desvio padrão muito alto nos dados de luminescência natural com LOE: foi constatado nas amostras dos pontos 24 (base) e 99. A dispersão dos sinais de luminescência sugere que o sedimento não teria sido exposto à luz solar por tempo suficientemente longo, isto é, provavelmente ocorreu deposição muito rápida, como sugerido por SRIVASTAVA et al. (2006) na Namíbia, ou então, a alta concentração de finos em suspensão na água 
teria causado turbidez e conseqüente obliteração dos raios solares, conforme GEMMELL (1994) e RHODES \& POWNALL (1994).

Para diminuir o desvio padrão, as medidas adicionais de luminescência natural foram repetidas 19 vezes. Após este procedimento as idades por LOE e TL das amostras provenientes dos pontos 24 (base) e 99 indicaram valores semelhantes e houve diminuição do desvio padrão. Essas amostras não apresentam nenhuma anomalia em teores de urânio, tório ou potássio, quando comparados aos de outras amostras da área de estudo.

b) Desvio padrão normal nos dados de luminescência natural com LOE: foi verificado na amostra do ponto 27. A LOE dos grãos de quartzo parece ter decaído muito lentamente com a exposição à luz solar, provavelmente em função de alguma anomalia cristalográfica, não identificada neste estudo.

\section{CONCLUSÕES}

Os depósitos quaternários do Alogrupo Alto Rio Paraná são colúvios e alúvios alojados em diversos compartimentos geomorfológicos da Bacia Hidrográfica do Alto Rio Paraná e testemunham importante hiato deposicional desde o fim da Era Mesozóica, seguido de evento intempérico e relativa quiescência tectônica. Datações absolutas pelos métodos da TL e LOE em sedimentos do Alogrupo Alto Rio Paraná, superpostos às rochas mesozóicas da Bacia do Paraná, indicaram idades quaternárias.

Amostras de diferentes profundidades nos depósitos coluviais da Aloformação Paranavaí sugerem acreção vertical de camadas sucessivas, pois as idades aumentam da superfície para a base dos perfis. Desse modo, as idades obtidas podem ser agrupadas para reconhecimento de diferentes gerações de colúvios. As distribuições espaciais desses depósitos com idades semelhantes sugerem forte vinculação com seus níveis topográficos de ocorrência. Por outro lado, os valores de isótopos radioativos naturais sugerem que existiriam dois grupos de sedimentos de proveniências distintas.

As amostras coletadas de terraços mais altos na Aloformação Paraná, na margem esquerda do Alto Rio Paraná, forneceram idades mais antigas que as amostras coletadas de terraços baixos, na margem direita, e registrariam histórias deposicionais diversas, talvez ligados a comportamentos neotectônicos diferentes, ou podem indicar a presença de terraços mais jovens embutidos.
As idades obtidas neste trabalho, juntamente com as já divulgadas por SALLUN \& SUGUIO (2006) e TATUMI et al. (2006), mostram que a instalação do Alto Rio Paraná iniciou-se, no mínimo, há $1 \mathrm{Ma}$ e possivelmente as fases mais importantes de coluviação estejam relacionadas a importantes mudanças paleoclimáticas globais do Pleistoceno.

\section{AGRADECIMENTOS}

À FAPESP, pela concessão de Bolsa de Doutorado (Processos 03/01737-5) à Alethéa Ernandes Martins Sallun e Auxílio à Pesquisa (Processo 03/09681-9). Ao CNPq, pela concessão de Bolsa de Produtividade a Kenitiro Suguio (Processo 304718/2003-3).

\section{REFERÊNCIAS}

AB'SABER, A.N. 1969. Os baixos chapadões do oeste paulista. São Paulo: Geomorfologia, 17: $1-8$.

AITKEN, M. J. 1985. Thermoluminescence dating. Academic Press, London, 359 p.

AITKEN, M.J. 1998. An introduction to optical dating. Oxford University Press, London, $230 \mathrm{p}$.

ANJOS, R.M.; VEIGA, R.; MACÁRIO, K.; CARVALHO, C.; SANCHES, N.; BASTOS, J.; GOMES, P.R.S. 2006. Radiometric analysis of Quaternary deposits from the southeastern Brazilian coast. Amsterdan: Marine Geology, 229: 29-43.

BATEZELLI A. 1998. Redefinição litoestratigráfica da unidade Araçatuba e da sua extensão regional na Bacia Bauru no Estado de São Paulo. Instituto de Geociências e Ciências Exatas, Universidade Estadual Paulista, Dissertação de Mestrado, 110 p.

BIGARELLA, J.J. \& ANDRADE G.O. 1965. Contribution to the study of the Brazilian Quaternary. In: H.E.Wright Jr. \& D. Frey (ed.) International Studies on the Quaternary. New York, Geological Society of America, p. 443-451 (Special Paper no. 84). 
BIZZI, L.A.; SCHOBBENHAUS, C.; GONÇALVES, J. H.; BAARS, F. J.; DELGADO, I. M.O.; ABRAM, M. B.; LEÃO NETO, R.; MUNIZ DE MATOS, G. M.; SCHNEIDER SANTOS, J. O. 2001. Mapas de Geologia, Tectônica e Recursos Minerais do Brasil: Sistema de Informações Geográficas - SIG. Brasília: CPRM, 4 CD-Rom (Escala 1:2500 000).

CARLOS, U.D.; RIBEIRO, F.B.; SAAD, A.R.; NICOLAI, S.H.A. 2004. Radioactivity distribution in some Permian sediments from the Irati and Corumbataí Formations of the Paraná Basin, Southeastern Brazil. Amsterdan: Applied Radiation and Isotopes, 60: 63-77.

CORRÊA, J.A.; PEIXOTO, C.A.M.; OLIVEIRA, C.C.; NETO, C.; JARDIM, F.G.; CORREIA FILHO, F.C.L., SCISLEWSKI, G.; HOENISCH, J.C.B.; CAVALCANTI, J.C.C.; FIGUEIREDO, J.A.; CAVALLON, L.A.; MONTEIRO, M.D.; CERQUEIRA, N.L.S.; SLONGO, T.T.; NOGUEIRA, V.L. 1976. Projeto Bodoquena. Goiânia: DNPM/CPRM, 247 p. (Relatório Final, v. 1).

DEHIRA, L.K.; BRAGA, T.O.; PONÇANO, W.L.; GIMENEZ FILHO, A.; PIRES NETO, A.G.; RICCOMINI, C.; MELO, M.S. 1981. Sedimentos cenozóicos na região de ParanavaíCianorte, Paraná. In: SBG, SIMPÓSIO REGIONAL DE GEOLOGIA, 3, Curitiba, Atas, 2: 14-24.

DEL'ARCO, J.O.; SILVA, R.H.; TARAPANOFF, I.; FREIRE, F.A.; PEREIRA, L.G.DA M.; SOUZA, S.L. DE; LUZ, D.S.DA; PALMEIRA, R.C.DE B.; TASSINARI, C.C.G. 1982. Geologia. In: BRASIL/Ministério das Minas e Energia. Secretaria-Geral, Projeto RADAMBRASIL: Folha SE.21 Corumbá e parte da Folha SE.20, Rio de Janeiro, p. 25-160.

DULLER, G.A.T. 2004. Luminescence dating of Quaternary sediments: recent advances. Chichester: Journal of Quaternary Science, 19:183-192.

FERNANDES, L.A. 1998. Estratigrafia e evolução geológica da parte oriental da Bacia Bauru
(Ks, Brasil). Instituto de Geociências, Universidade de São Paulo, São Paulo, Tese de Doutorado, $232 \mathrm{p}$.

FERNANDES, L.A. \& COIMBRA, A.M. 1996. A Bacia Bauru (Cretáceo Superior, Brasil). Rio de Janeiro: Anais da Academia Brasileira de Ciências, 68: 195-205.

GASPARETTO, N. V. L. 1999. As formações superficiais do noroeste do Paraná e sua relação com o Arenito Caiuá. Instituto de Geociências, Universidade de São Paulo, São Paulo, Tese de Doutorado, $172 \mathrm{p}$.

GEMMELL, A.M.D. 1994. Environmental controls on the TL age of modern zero-age proglacial outwash sediments. Amsterdan: Quaternary Geochronology, 13: 485-489.

GONÇALVES, A. \& SCHNEIDER, R. L. 1970. Geologia do centro-leste de Mato Grosso. Ponta Grossa: PETROBRÁS-DESUL, 43 p. (Relatório Técnico Interno, 394).

JUSTUS, J.O. 1985. Subsídios para interpretação morfogenética através da utilização de imagens de radar. Universidade Federal da Bahia, Salvador, Dissertação de Mestrado, $204 \mathrm{p}$.

KAVALERIDZE, W. C. 1963. Erosão na região noroeste do Estado do Paraná e projeto para sua eliminação. In: SVOPEP, CONGRESSO NACIONAL DE PRESERVAÇÃO DO SOLO, 2, Belo Horizonte, Anais, 34 p.

LI, S-H. \& WINTLE, A.G. 1992. Luminescence sensivity change due to bleaching of sediments. Oxford: Nuclear Tracks Radiation Measurement, 20(4): 567-57.

LIAN, O.B. \& ROBERTS, R.G. 2006. Dating the Quaternary: progress in luminescence dating of sediments. Amsterdan: Quaternary Science Review, 25(19/20): 2449-2468.

MEJDAHL, V. 1979. Thermoluminescence dating: beta-dose attenuation in quartz grains. Oxford: Archaeometry, 21: 61-72. 
MINEROPAR - MINERAIS DO PARANÁ S.A. 2001. Mapa Geológico do Paraná. Curitiba: Secretaria de Indústria, Comércio e do Turismo do Estado do Paraná. (Escala:1:1.000.000).

OLIVA, L.A.; OLIVATTI, O.; RIBEIRO FILHO, W.; SCHOBBENHAUS FILHO, C. 1979. Carta geológica do Brasil ao milionésimo: folha Cuaiabá (SD21). Brasília: DNPM, Escala: 1:1.000.000 (Relatório Técnico).

OLIVEIRA, M.A.M. 1964. Reconhecimento Geológico Expedito na Região do Alto Paraguai. Ponta Grossa: PETROBRÁS-DESUL, 47 p. (Relatório Técnico Interno).

OLIVEIRA, M.A.M. \& MÜHLMANN, H. 1967. Observations on the geology of Chapada dos Guimarães, Mato Grosso. Ponta Grossa: PETROBRÁS-DESUL, 362 p. (Relatório Técnico Interno).

POPP, J.H. \& BIGARELLA, J.J. 1975. Formações cenozóicas do noroeste do Paraná. Rio de Janeiro: Anais da Academia Brasileira de Ciências, 47: 465-472.

PRESCOTT, J.R. \& ROBERTSON, G. B. 1997. Sediment dating by luminescence: a review. Oxford: Radiation Measurements, 27(5/6): 893-922.

RHODES, E.J. \& POWNALL, L. 1994. Zeroing of the OSL signal in quartz from young glaciofluvial sediments. Oxford: Radiation Measurements, 23:581-586.

RIBEIRO, F.B. \& ROQUE, A. 2001. Vertical distributions of uranium, thorium and potassium and of volumetric heat production rates in the sediments of the São Francisco basin, Central Brazil. Oxford: Applied Radiation and Isotopes, 55: 393-405.

ROQUE, A. \& RIBEIRO, F.B. 1997. Radioactivity and radiogenic heat production in the sediments of the São Francisco sedimentary basin, Central Brazil. Oxford: Applied Radiation and Isotopes, 48: 413-422.
SALLUN, A.E.M. 2003. Depósitos cenozóicos da região entre Marília e Presidente Prudente (SP). 2003. Instituto de Geociências, Universidade de São Paulo, São Paulo, Dissertação de Mestrado, $171 \mathrm{p}$.

SALLUN, A.E.M \& SUGUIO, K. 2006. Depósitos quaternários da região entre Marília e Presidente Prudente (SP). São Paulo: Revista Brasileira de Geociências, 36(3): 385-395.

SALLUN, A.E.M.; SUGUIO, K.; STEVAUX, J.C. 2007a. Proposição formal do Alogrupo Alto Rio Paraná (SP, PR e MS). São Paulo: Geologia USP - Série Científica, 7(2): 49-70.

SALLUN, A. E. M.; SUGUIO, K.; TATUMI, S. H. ; YEE, M. ; SANTOS, J. ; BARRETO, A. M. F. 2007b. Datação absoluta de depósitos quaternários brasileiros por luminescência. São Paulo: Revista Brasileira de Geociências, 37(2):401-412.

SALLUN, A.E.M.; SUGUIO, K.; SALLUN FILHO, W. 2007c. Geoprocessamento para caracterização da Aloformação Paranavaí. Rio de Janeiro: Revista Brasileira de Cartografia, 59(3): 303-313.

SANTOS, M.L. 1997. Estratigrafia e evolução do sistema siliciclástico do rio Paraná no seu curso superior: ênfase à arquitetura dos depósitos, variações longitudinal das fácies e processos sedimentares. Instituto de Geociências, Universidade Federal do Rio Grande do Sul, Porto Alegre, Tese de Doutorado, $250 \mathrm{p}$.

SCHOBBENHAUS FILHO, C. \& OLIVA, L.A. 1979. Carta geológica do Brasil ao milionésimo: Folha Corumbá (SE21). Brasília: DNPM, Escala 1:1.000.000 (Relatório Técnico).

SRIVASTAVA, P.; BROOK, G.A.; MARAIS, E.; MORTHEKAI, P.; SINGHVI, A.K. 2006. Depositional environment and OSL chronology of the Homeb silt deposits, Kuiseb River, Namíbia. San Diego: Quaternary Research, 65: 478-491.

STEVAUX, J.C. 1993. O Rio Paraná: geomorfogênese, sedimentação e evolução quaternária de 
seu curso superior (região de Porto Rico, PR). Tese de Doutorado, Instituto de Geociências, Universidade de São Paulo, São Paulo, 242 p.

SUAREZ, J.M. 1976. Contribuição à geologia do extremo oeste do estado de São Paulo - parte 2. Rio de Janeiro: Boletim Geográfico, 34(248): 119-155.

SUAREZ, J.M. A. 1991. Localização das cidades no extremo oeste do Estado de São Paulo
(Brasil) e seus problemas. In: UAEM, ENCUENTRO DE GEOGRAFOS DE AMERICA LATINA, 3, Toluca, Memória, p. 323-336.

TATUMI, S. H.; GOZZI, G.; YEE, M.; OLIVEIRA, V. I.; SALLUN, A. E. M.; SUGUIO, K. 2006. Luminescence dating of Quaternary deposits in geology in Brazil. Ashford: Radiation Protection Dosimetry, 119(1-4): 462-469.

Endereço dos autores:

Alethea Ernandes Martins Sallun - Instituto Geológico, Secretaria do Meio Ambiente do Estado de São Paulo, Avenida Miguel Stéfano, 3900, CEP 04301-903, Água Funda, São Paulo, SP.

E-mail: alethea@igeologico.sp.gov.br

Kenitiro Suguio - Departamento de Geologia Sedimentar e Ambiental, Programa de Pós-graduação em Geologia Sedimentar, Instituto de Geociências, Universidade de São Paulo, Rua do Lago, 562, CEP 05508080, São Paulo, SP e Centro de Pós-Graduação, Pesquisa e Extensão (CEPPE), Universidade Guarulhos (UnG), Rua Dr. Nilo Peçanha, 81 (Prédio U - 6 andar) - CEP 07023-070, Guarulhos, SP.

E-mail: kenitirosuguio@hotmail.com 